\title{
LA ICONOGRAFÍAY EL CONCEPTO DEL TIEMPO EN LOS MOSAICOS DE HISPANIA - ROMANA
}

\author{
Dr. Mohamed A. R. Abouarab, Ph.D. \\ Profesor de Aroueología Greco Romana e Copta, \\ Departamento de AROUEOLOGÍA, UniverSidAd de KAFRELSHEIKH, EGIPTO. \\ Lic. Dayanna Lee Carbonel Arana \\ Especialista en Gestión de Patrimonio Cultural. Lima - Perú \\ dayannacarbonel@gmail.com
}

\section{RESUMEN}

En el presente artículo se analizará el concepto de la iconografía a través del tiempo y su evolución hasta el mosaico romano hispano. Las cuales se desarrollan en tres partes: la primera será la historia de la conquista de los romanos hacia Hispania. La segunda parte analizará el concepto de "tiempo" en Roma y en la tercera parte analizará la iconografía en el tiempo y su evolución del mosaico en Hispania.

Palabras Clave: iconografía, mosaico, tiempo, Hispania, romana.

\begin{abstract}
In this paper, the concept of iconography will be analyzed as well as its evolution up to the Hispanic Roman mosaic will be discussed. The discussion of the concept will be divided into three main parts. First, the paper will examine the history of the Roman Invasion of Hispania. Second, the concept of time in Rome will be investigated. Finally, the concept of iconography in time and the evolution of mosaic in Hispania will be discussed.
\end{abstract}

KeYwords: iconography, mosaic, time, Hispania, roman. 


\section{INTRODUCCIÓN}

La conquista Romana en Hispania perduró hasta la entrada de las primeras tribus bárbaras, en el siglo V d.c., realizando una fuerte influencia (Blázquez, 1993: 70-92.) durante siete siglos de dominación hasta llegar a formar una población homogénea en Hispania conocida como "hispanos - romana" (Ruiz 1982: 17-27, 97-11). Durante este largo periodo, los romanos introducen en Hispania toda una serie de cambios culturales también conocidos como la romanización (Schnell 1992: 65). En una de las definiciones más simples se entiende al concepto de romanización (Albornoz 1949: 11) como: "el proceso de introducción de la cultura Roma Antigua en Hispania".

En el tiempo que Roma establecía sus dominios sobre la Península Ibérica, también imponía su particular forma de entender la vida en diferentes aspectos: la economía, la legislación (Domingo 2008: 15-20), la infraestructura (arquitectura) que emplearon para crear y expandir su imperio. Así como las diferentes manifestaciones artísticas (Ferrán, 1999: 65-73) que llegaron a desarrollar y que hoy en día representa un importante legado arqueológico y cultural.

La Hispania - Romana se dividió en tres provincias ubicadas en la antigua Báltica, desde el siglo II de nuestra Era. Registrando una de las piezas de musivaria más únicas de la península. En la antigua Península Itálica a escasos kilómetros de Sevilla se encuentra la Casa del Planetario siendo la primera colonia fundada por Roma en la Hispania, ordenado por el célebre Escipión el Africano, la residencia "ahora en ruinas" fue construida en la época de Adriano (117 y el 130 d.c.).

Esta influencia también forma parte de nuestro análisis, así como el estilo minusvaria (Sandoval 2004: 1-88) y la conceptualización del tiempo. Se promueve el desarrollo de un repertorio iconográfico el cual será parte del presente artículo.

\section{El CONCEPTO DE TIEMPO EN LA ANTIGUA ROMA}

El concepto de tiempo es utilizado para denominar la magnitud de carácter físico que se emplea para realizar la medición de lo que dura algo que es susceptible de cambio. Ello siempre capto gran interés a los largo de la historia hasta la llegada de los romanos.

En la vida cotidiana el tiempo se medía por el calendario lunar pero luego con las reformas que se realizaron en el Imperio, se trató de ajustar la medición del tiempo con el calendario solar que era el que determinaba el curso natural del año (Rüpke 2011: VI, 226).

Podemos definir el "tiempo" de dos formas: la primera como el establecimiento cronológico a través de los días, meses y años; y la segunda como personificaciones en las Figuras literarias. Durante el desarrollo de esta parte del artículo, vamos a analizar ambos conceptos tomando como ejemplos el estilo minusvaria de Hispania - Romana (Mélida 1935: 709-710).

El Imperio fue comparado con el universo y el Emperador con el maestro que regula el universo. El paso del tiempo y la sucesión de días, meses y estaciones del año ilustran la eterna renovación del universo, y por lo tanto, el Imperio Romano (Fuente: Mosaicos de Túnez: Tesoros de África romana, Aïcha Abed, 2006 Instituto de Conservación Getty). El mosaico de abajo muestra un calendario con ilustraciones de los meses y las estaciones establecidas en medio de escenas bucólicas y mitológicas. (Figura 1 y 2)

Cada mes es representado por un signo del zodíaco y una deidad tutelar o deidad cuyo nacimiento está asociado a ese mes, también se hace alusiones a las fiestas religiosas. El mosaico celebra la renovación del ciclo de la naturaleza que con la ayuda de los dioses proporcionaría al propietario de la villa con el sustento y la riqueza. (Figura 3, 4 y 5) 
Mohamed Abouarab y Dayanna Carbonel / La iconografía y el concepto del tiempo...

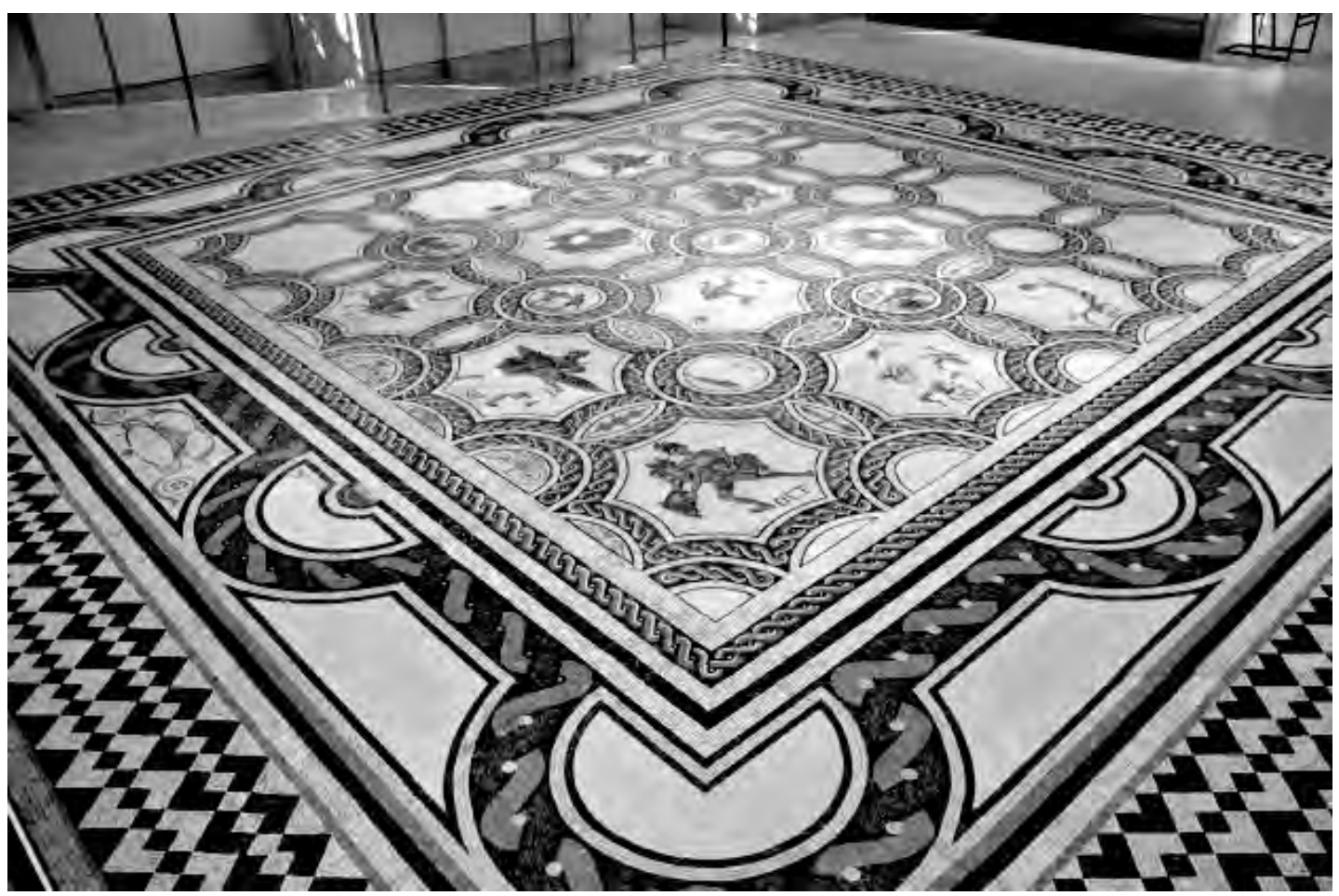

Figura 1. Mosaico de las estaciones y los meses, siglo III., que se encuentran en Hellín (Albacete), Museo Arqueológico Nacional de España, Madrid

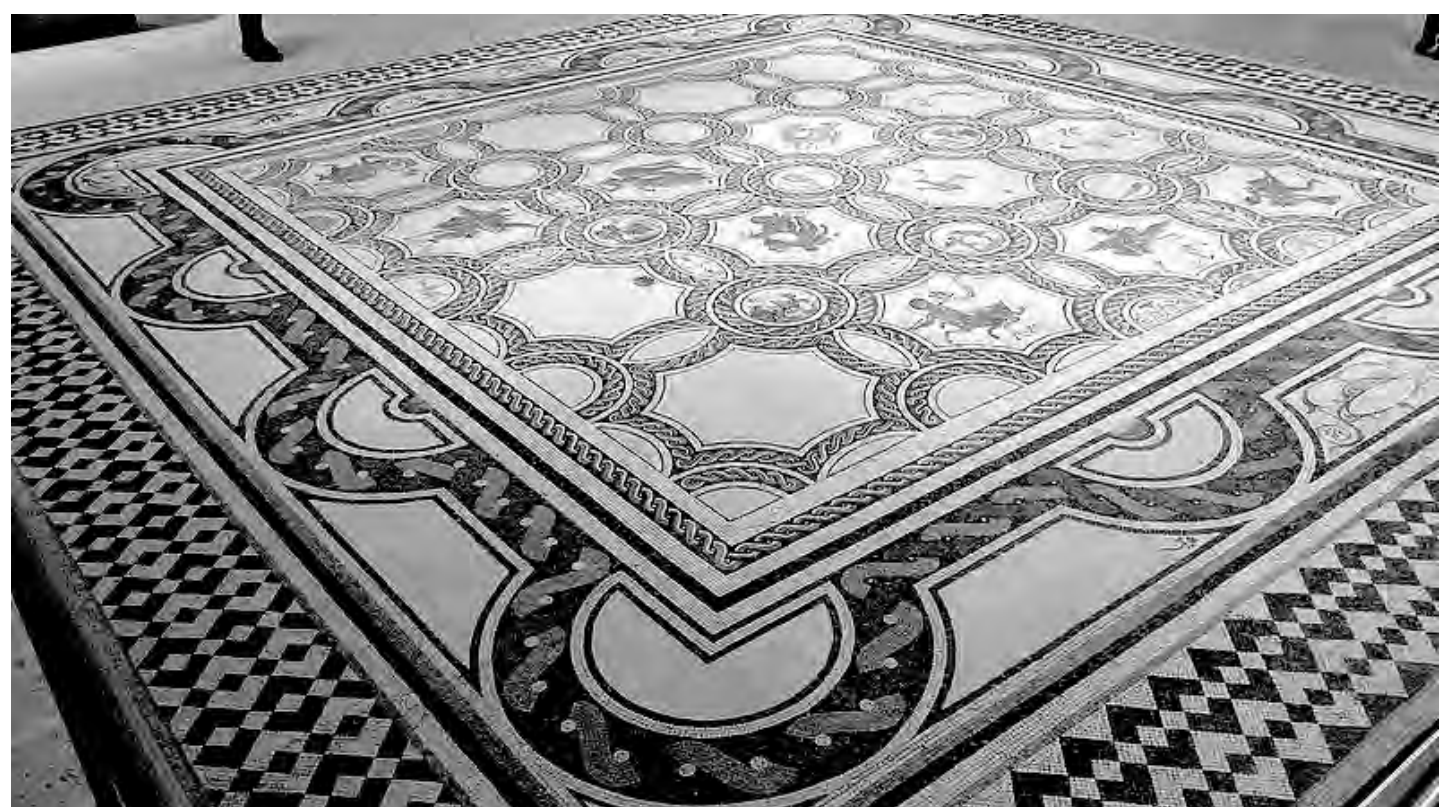

Figura 2. Mosaico de las estaciones y los meses, siglo III, que se encuentran en Hellín (Albacete), Museo Arqueológico Nacional de España, Madrid 


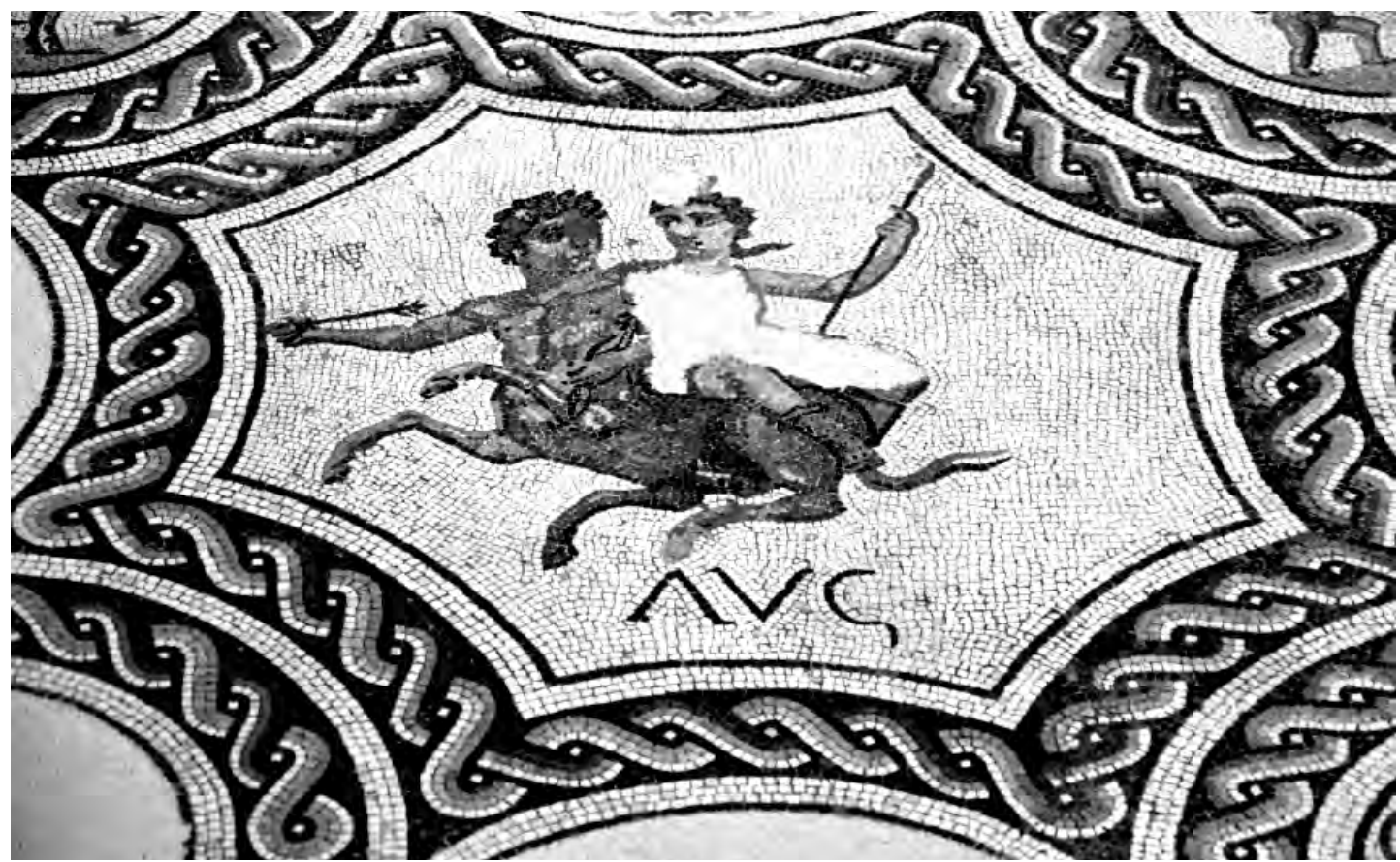

Figura 3. Detalle del mosaico de las estaciones y los meses, siglo III, que se encuentran en Hellín (Albacete), Museo Arqueológico Nacional de España, Madrid

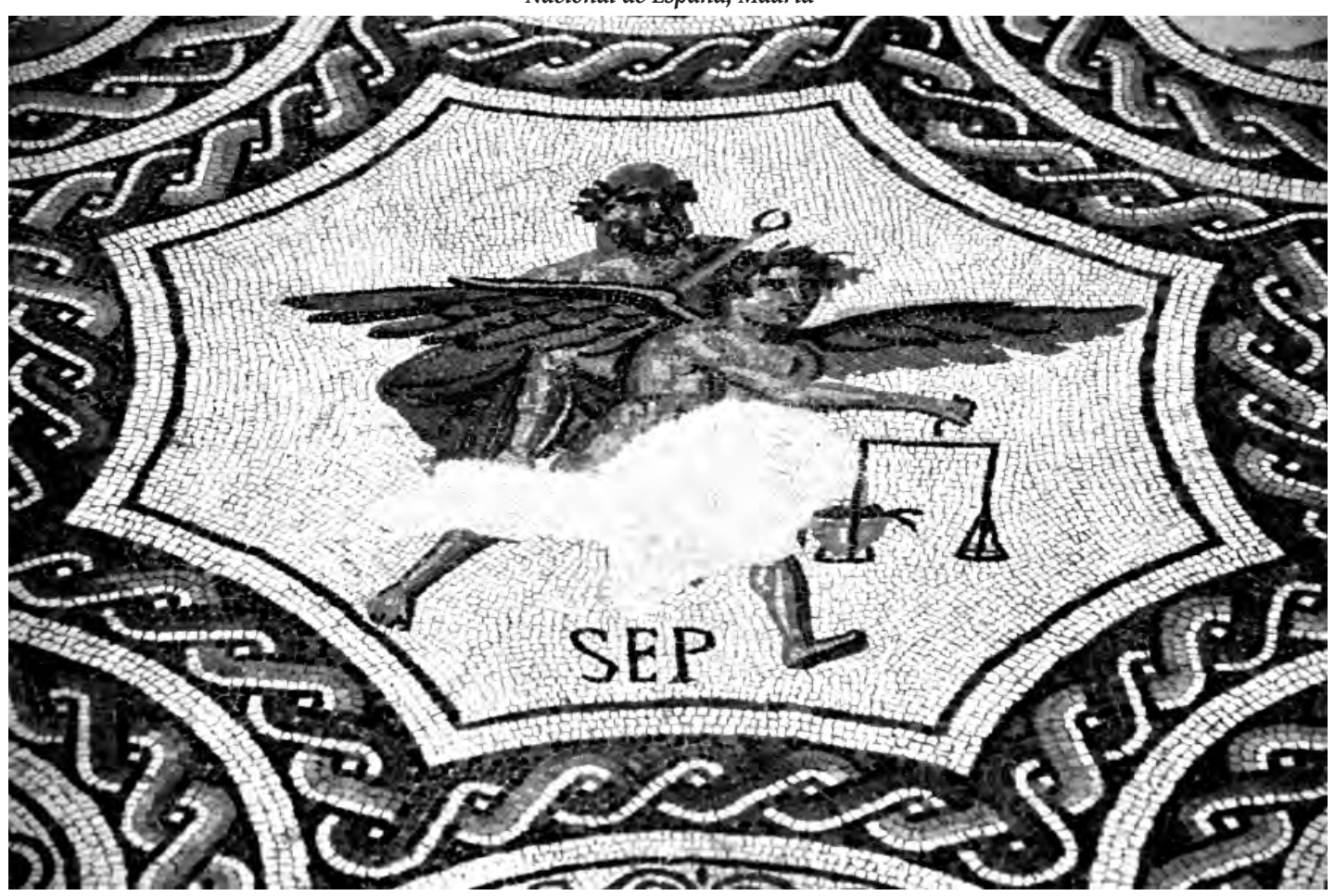

Figura 4. Detalle del mosaico de las estaciones y los meses, siglo III, que se encuentran en Hellín (Albacete), Museo Arqueológico Nacional de España, Madrid 
Mohamed Abouarab y Dayanna Carbonel / La iconografía y el concepto del tiempo...

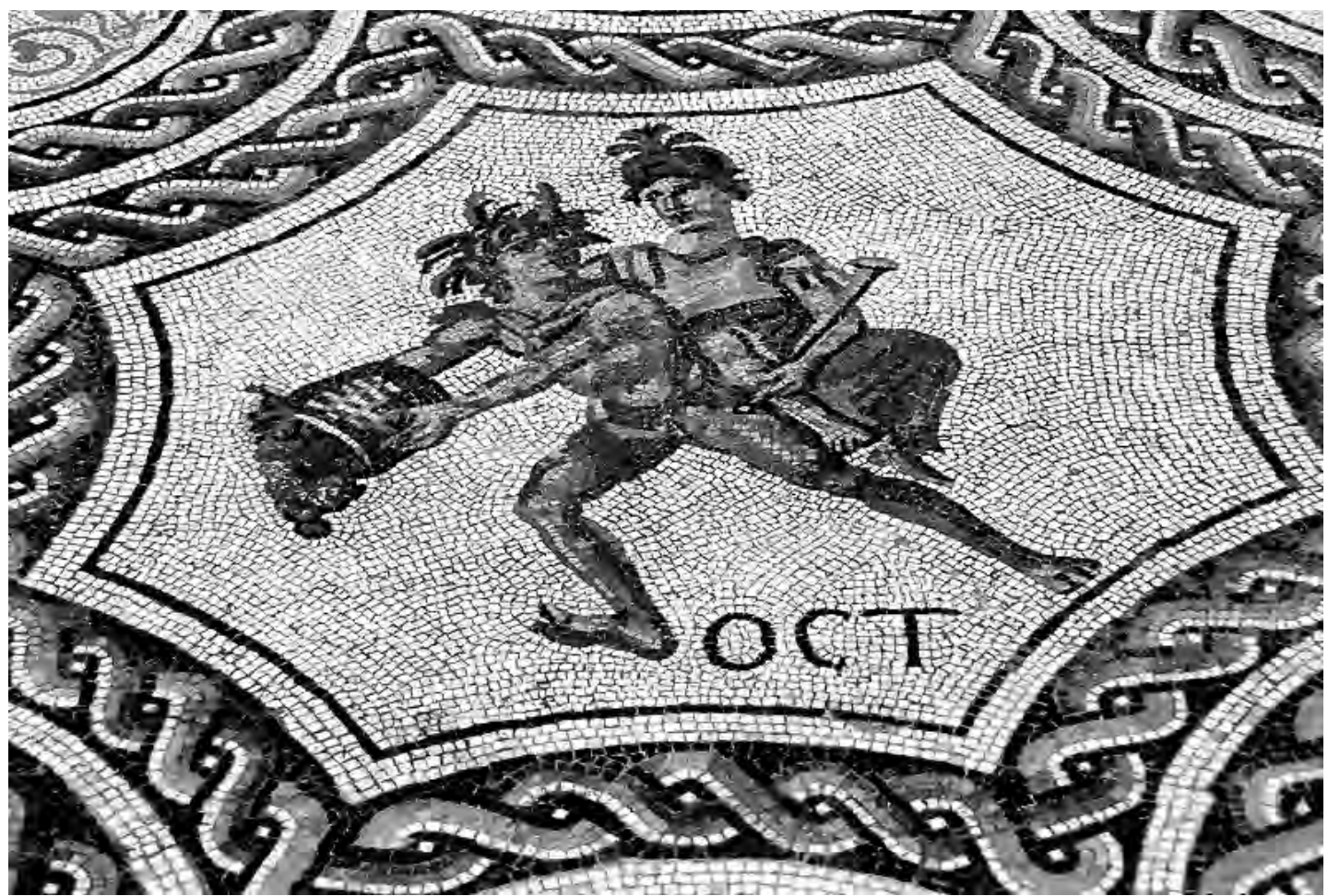

Figura 5. Detalle del mosaico de las estaciones y los meses, siglo III, que se encuentran en Hellín (Albacete), Museo Arqueológico Nacional de España, Madrid

Uno de los elementos patrimoniales más representativos del arte clásico son los mosaicos de las estaciones, siendo los más famosos los procedentes de Vienne (Lafaye 1909, nº 187: 43), Sainte Colombe, Saint-Romain de Gal en la Galia Narbonense y Aquitania. Así como también los de Lyon (Blanchet 1909, $n^{\circ} 734: 10$ ), Brotonne, Orbe y Tourmont en las provincias más al norte como por ejemplo Treyes en donde se halló representaciones de dioses. En África las figuras emblemáticas se hallan de forma repetitiva similares a los mosaicos Cartagineses. Para el mes de mayo por ejemplo lo presenta un hombre joven provisto de un cesto con flores y en el mes de junio una mujer con un cesto de frutos. En otros mosaicos de la misma ciudad las representaciones que quedan son figuras de mujeres que no ejecutan labores muy concretas. Más significativo es un tercer mosaico cartaginés en el que hallamos lo que sigue (Figura 6):

Januarius: representado por un ave (gallo), una cesta (canasta) con panes y una rama de orquidea (Orchidaceae) sin hojas.

Februarius: presentado por una herramienta agrícola (azada), un pez y un ave (Anas platyrhynchos domesticus) también conocido como pato.

Martius: un personaje transportando un cabrito.

Aprilis: pastor crióforo.

Maius: una forma femenina, llevando un cesto de rosas.

Junius: un personaje corriendo con una cesta llena de flores.

Julius: un personaje llevando un haz de espigas.

Augustus: lleva un plato de higos.

September: un personaje con un calathus repleto de frutos. 
October: un personaje ostenta una liebre recién cazada.

November: un personaje lleva también un cesto con frutos.

December: un personaje lleva un cesto a la espalda y unas varillas de liga

El Calendario de los Agricultores (Menologium Rusticum Colotianum), data entre 19-65 d.C. en Roma y actualmente se muestra en el Museo della Civiltà Romana. Cada lado tiene los nombres de tres meses del año. Para cada mes, a partir de la parte superior: el número de días en que; el día en que las nonas (día de la primera cuarta parte de la Luna) se cae; la duración de la noche día y expresada en horas; el signo del zodiaco; la divinidad protector; trabajar para ser atendido en los campos y en las fiestas más importantes. (Figura 7)

La rústica fenomenología (almanaques agrícolas) es un tipo de calendario romano, que proporcionó información mensual sobre las condiciones y actividades relacionadas con la agricultura. Ellos fueron expuestos en público en forma de inscripciones.

Ejemplos de tales calendarios que han llegado hasta nuestros días son los Menologium (Hadrll 1997: 3-22) rusticum Colotianum (Meslin 1978: 55-74) y Menologium rusticum Vallense, que data desde el periodo 19-65 dC (Salzman 1990: 170) o entre 36 a 39 y el final del primer siglo después de Cristo (Patrich 2011: 84, nota 53). Ambos fueron descubiertos en el siglo XVI, pero el Menologium Vallense se pierde luego (Sandys 1919: 174).

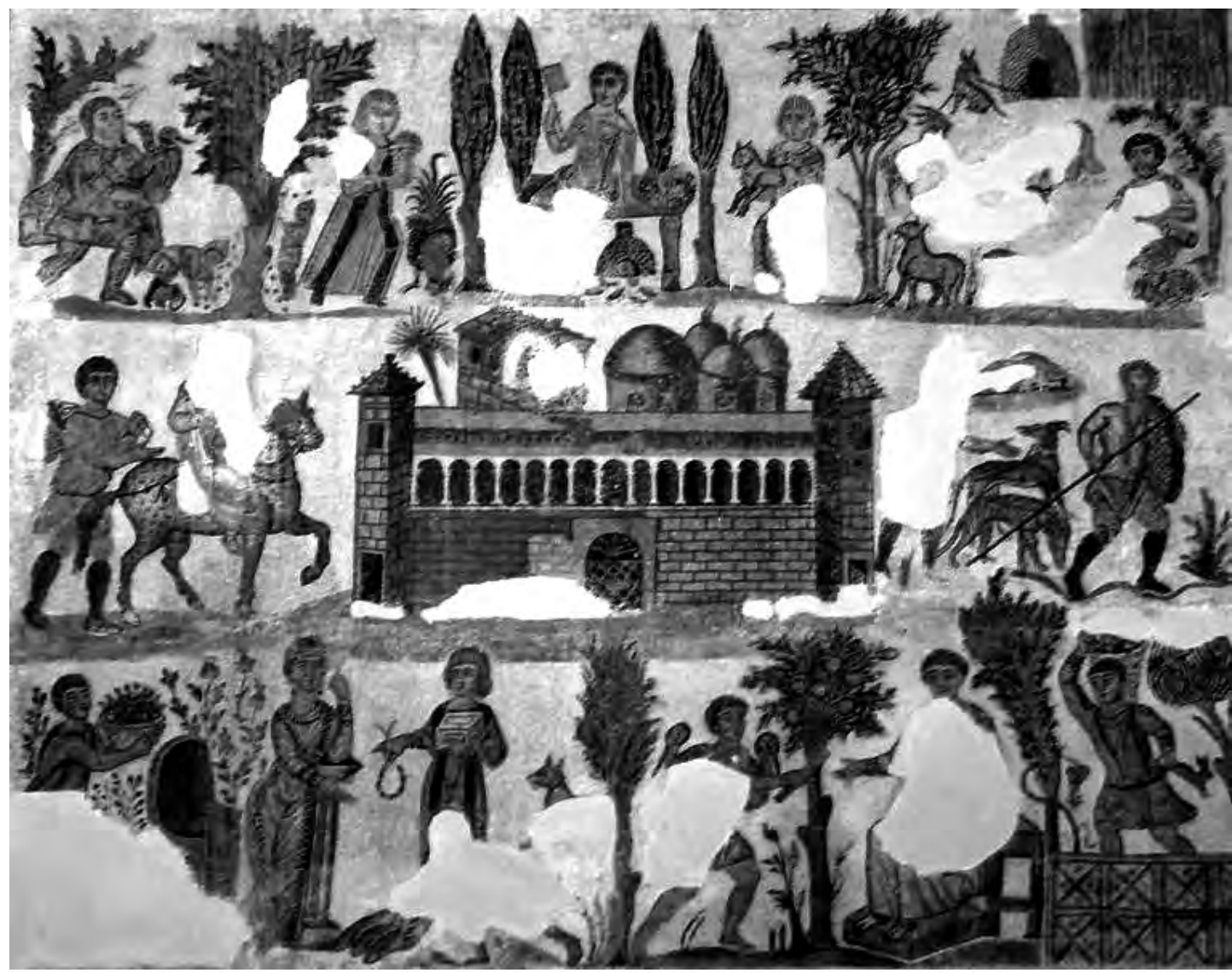

Figura 6. Mosaico Dominus Julio de Cartago segolo IV-V, ahora alojado en el Museo del Bardo en Túnez 


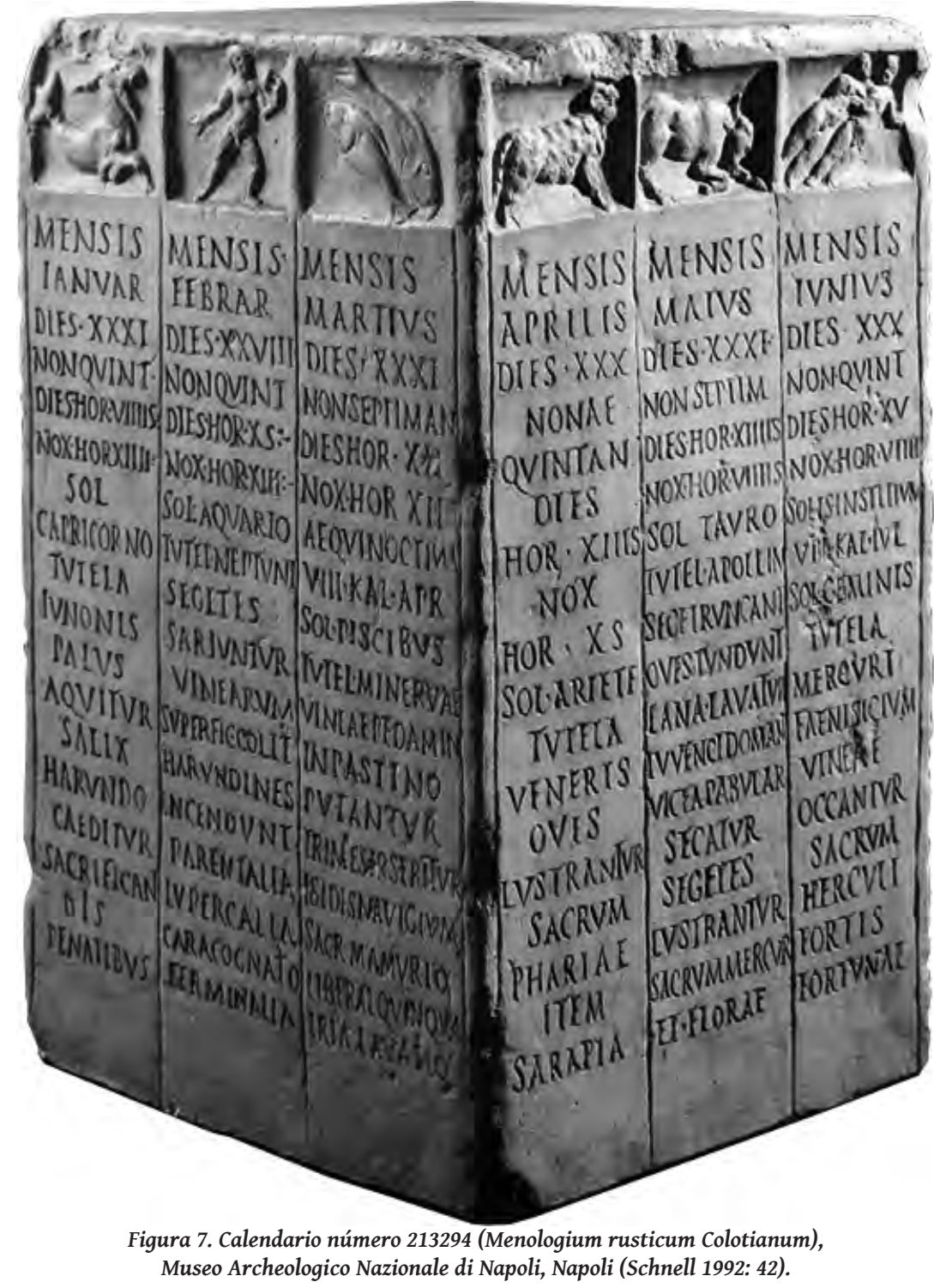

El Menologium (Woolf 2001: 173-186, 106-129) rusticum Colotianum fue descubierto por Angelo Colocci y en la actualidad se encuentra expuesto en el Museo Arqueológico Nacional de Nápoles (Sandys 1919: 174). A parece en los cuatro lados de una base de altar de mármol, escrito en doce columnas (una por mes). Cada columna contiene (Woolf 2001: 173-186, 2005: 106-129):

Un signo del zodíaco.

El nombre del mes.

El número de días de ese mes.

La fecha en que el Nonae cayó (el quinto o séptimo día, dependiendo del mes).

El número de horas de luz y oscuridad en los días de ese mes. 
La casa astrológica atravesada por el Sol.

La deidad tutelar del mes.

Las actividades a realizar en la agricultura.

Fiestas religiosas que un agricultor se ve obligado a cumplir (Egbert 1896: 368).

Enero: Salix, harundo caeditur, sacrificant dis penatibus.

Febrero: Sariuntur vinearum, superficium colitur, harundines incendunt.

Marzo: Vineae pedamina in pastino putantur trimenstr seritur.

Abril: Oves seritur.

Mayo: Segetes runcantur, oves tundunt, lana lavatur, juvenci domant, vicea pabular secatur, segetes lustrantur.

Junio: Faenisicium, vineae occantur.

Julio: Messes hordiariae et fabariae.

Agosto: Messes frumentariae, triticariae, stupulae incendunt.

Septiembre: Dolea picantur, poma leguntur, arborum oblaqueatio.

Octubre: Vindemiae.

Noviembre: Sementes triticarie et hordiariae, scrobatis arborum.

Diciembre: Vineas stercorantur, faba seritur, materias decientes, oliva legitur.

Las villas que estaban en tierras de cultivo mostraron a menudo mosaicos y murales que representan las actividades agrícolas de temporada o mensual, en cierta medida las representaciones de rústica fenomenología (Marzano 2007:297).

Van L. Johnson sugirió que la forma de cuatro lados de la fenomenología mantuvo un ciclo original de "años" vacaciones en Roma o en base a cuatro meses (Johnson 1960: 110).

\section{ESTUDIO ICONOGRÁFICO}

\section{Definición de Mosaico}

El mosaico o minusvaria es un elemento decorativo característico de las ciudades de la Antigua Roma. Los mosaicos podían adornar las paredes y techos de los edificios. En especial los encontramos en las "domus" y las "villae", dentro de las viviendas de las familias patricias, pero también los encontramos en los palacios de los emperadores romanos. Los mosaicos estaban distribuidos entre las habitaciones de la estancia de la casa romana.

La elaboración del mosaico era realizado con pequeños trozos de piedra llamados teselas de allí proviene el nombre originario en latín opus teselatum y dependiendo del tamaño de las teselas y su ubicación el mosaico tenía un nombre diferente:

Opus vermiculatum. Piedras muy pequeñitas, donde el artista tenía que dibujar con una gran precisión los objetos que formaban el repertorio iconográfico.

Opus musivum. Mosaicos que se hacían para las paredes.

Opus sectile. Se usan piedras de diferentes tamaños pero más grandes que las anteriores, además se recortaban placas de mármol para componer las Figuras.

Opus signinum, de Signia. Se obtenía con los desechos un polvo coloreado que al mezclarlo con la cal daba un cemento rojizo muy duro e impermeable. Este producto se empleó bastante en toda Italia y en Occidente para crear los suelos y como revestimiento de piscinas (estanques para peces), cubas de salazón, aljibes, etc. 


\section{Cronología:}

La palabra mosaico proviene etimológicamente de la palabra griega "musa". Según el historiador griego del S.II Pausanias, al principio las musas fueron tres: Aedea (el canto, la voz), Meletea (la meditación) y Mnemea (la memoria). Juntas representaban las precondiciones del arte poético en la práctica del culto religioso. En el antiguo mundo clásico Griego el arte de los mosaicos era tan representativo y hermoso que podía estar inspirado en las musas.

En un inicio los mosaicos eran utilizados para decorar un espacio libre ya sea en la pared o en el suelo. Constaba con colocar de forma armoniosa pequeños pedazos de teselas de manera tal que formaran una Figura. En los orígenes de los mosaicos fueron de piedra, pasando por el mármol y empleando técnicas más perfeccionada como el vidrio, esta última es conocida también como vitrales las cuales tenían doble función: la primera decorativa y la segunda permitía ingresar la luz de manera diferente

A través del tiempo la elaboración del mosaico requirió de manos especialistas que afinen los acabados asi como también realicen piezas cada vez más complejas. El personal calificado para hacerlo tenía una funcion especifica en el taller: El diseñador "el pictor imaginarius" el primer ayudante "musaearius", el especialista en colocar el diseño sobre la pared o suelo "pictor parietarias", el que realizaba los tallados "tessellador", el que preparaba las teselas dándole forma y acabado "lapidarius".

$\mathrm{El}$ arte de elaborar mosaicos en Roma eran llevados a niveles de alto perfeccionamiento y estilos, creando tipologías para su diferenciación, los tipos ó tambien llamados opus era referente a la colocación de los mosaicos; entre ellos el mosaico guijarro, opus signinum. Opus scutulatum, opus segmentatum, opus sectile, opus tessellatum, opus vermiculatum, opus musivum.

Es difícil delimitar con precisión las fechas exactas del arte mosaico musivaria romana puesto que las modas y los estilos perduraron durante largo tiempo, aunque es necesario hacer una aproximación para conocer el momento de construcción de este espacio doméstico. Analizando los detalles iconográficos y estilísticos, que si bien no son definitivos pueden servirnos de aproximación para su datación.

El Mosaico de Puente Melchor se podría fechar hacia finales del siglo II o quizás en el primer cuarto del siglo III d.C. (Lavado 2010: 110), sus peculiaridades, características formales y estilísticas responden a este período, como por ejemplo el uso del color, la existencia de Figuras mitológicas y la presencia de registros geométricos como la roseta de triángulos curvilíneos, todos ellos elementos de interés que de forma combinada, permiten realizar una aproximación a la fase de construcción.

Los mosaicos romanos más antiguos de Hispania fueron fechados a finales de la República Romana, se han encontrado en Carthago Nova, Cástulo (Jaén), Itálica (Pedraz 1991: 393-406, 531-540) (Sevilla (Panagiotopoulou 1994: 369-383, Blanco 1978:a 20-27, Gómez 1984: 60-62, Monteagudo 2001: 130-146)) y en el valle del Duero. Pavimentos de opus signinum se han descubierto en la capital de la provincia Tarraconense, en Tarraco, en Baetulo, en Sagunto y en Andión (Navarra).

Están fabricados en blanco y negro. A veces llevan inscripciones. Los lithostrata, crustae y opera signina con motivos decorativos o con inscripciones, hallados en el puerto de Emporiae, se fechan en la segunda mitad del siglo I.

En estos años se datan también grandes emblemas confeccionados en blanco y negro, decorados con motivos geométricos, descubiertos en las casas de esta ciudad. Son importados los emblemas fabricados en vermiculatum polícromo. Son cinco; uno de ellos se decoró con peces grandes y un gato 
matando a un faisán en los escalones de una despensa; un segundo tiene una máscara cómica, colocada sobre peana prismática; un tercero tiene una perdiz sacando un collar de un joyero.

\section{La técnica de realización de los mosaicos romanos}

El proceso de la fabricación era complejo (Sandoval 2004: 125-138) debido a que las habitaciones no contaban con pavimentos y se procedía a colocar varias capas antes de la colocación de las teselas.

Para su elaboración se recurría a utilizar distintas herramientas. Aquí citamos algunas de ellas.

Con estas tres herramientas se tallaban las teselas:

1. Martillo.

2. Tallador.

3. Tenazas.

Con estas dos se coloraban y se aplanaba el mortero:

1. Paletas.

2. Espátulas.

En la Antigua Roma existían Talleres especializados donde se construían los mosaicos. En los talleres trabajaba un equipo de operarios que desempeñaban las distintas tareas para la realización de los mosaicos. Seguramente estos talleres eran talleres itinerantes o temporales que se desplazaban de un lugar a otro para realizar su trabajo, por eso se encuentran mosaicos iguales o parecidos en distintos lugares del Imperio. Tenemos datos de los diferentes oficios del taller, podemos citar:

Pictor Imaginarius: Diseñaba el dibujo, realizaba las partes más difíciles y dirigía al equipo de artesanos.

Musivarius: Se encargaba de hacer las perforaciones donde luego se colocaban las teselas.

Tesselarius: Tallaba las teselas y las colocaba en el mortero

\section{Proceso y técnica de elaboración de los mosaicos en el mundo romano:}

Los mosaicos eran realizados según las técnicas tradicionales romanas, están a cargo de un técnico mosaiquista que sigue el boceto del diseñador.

El artesano del mosaico actual, por lo general, lleva a la práctica todos los procesos que requiere la confección del mismo, de principio a fin, al contrario de lo que ocurría en época romana, en donde el trabajo se hacía en equipo, en un taller llamado officinal, donde cada operario tenía asignada una tarea determinada.

El mundo romano reguló estrictamente los nombres de los operarios y la función que desempeñaban en la preparaciónón y posterior realización de los mosaicos. Así, el pictor imaginarius era el artista que hacía el diseño del mosaico; el musaearius era el ayudante más directo, sobre el cual recaía la tarea de controlar los aspectos mas cotidianos de la marcha de la obra; el pictor parietarius pasaba el diseño sobre el suelo o la pared; el tessellator realizaba los mosaicos, siguiendo el dibujo marcado; el lapidarius preparaba las teselas cortando las de placas de mármol; y el calcis coctor era el operario encargado de la preparación de la cal.

Plinio "El Viejo" dejó constancia en sus escritos de cómo se preparaban las superficies para recibir el mosaico, la base sustentadora más común era el mortero. Los suelos de los edificios romanos sopor- 
Mohamed Abouarab y Dayanna Carbonel / La iconografía y el concepto del tiempo...

taban de dos a tres capas de mortero, sobre las que se aplicaba una óptima capa adherente o nucleus como base para el teselado. Era importante la calidad del nivelado, debiéndose realizar con el máximo esmero el raseado de las superficies, la finalidad era obtener un pavimento grueso, consistente y sólido, donde todas las capas quedaran fuertemente unidas entre sí.

\section{Tipos de mosaicos}

Si seguimos la clasificación de Jose María Blazquez Martínez en su artículo "Los Mosaicos Romanos en Hispania", podemos dividir los mosaicos en: mosaicos en blanco y negro y mosaicos polícromos. Durante los dos primeros siglos imperiales predominó en Hispania el mosaico en blanco y negro, que sigue modelos de Italia. Las relaciones comerciales que mantenían las provincias hispanas con Italia provocaron la llegada de ciertas influencias entre las que se encontraban el gusto por lo itálico. Si bien los primeros en desarrollarse fueron los mosaicos en blanco y negro, a partir del siglo III, se generalizan los grandes mosaicos polícromos con temática variada, en ambos hay temas geométricos y temas mitológicos.

Los mosaicos en blanco y negro se documentan hasta comienzos del siglo III, en la región comprendida entre Barcino y Sagunto. Probablemente trabajaban talleres ambulantes. En algunos ejemplares hay una ligera policromía. Un buen ejemplar de esta técnica artística es el mosaico de Valencia (Carreres 1989: 554, Taracena 1947: 160, Figuraura 152, Pidal 1955: 767 y SS., Figura 537: 540-552.) con cabeza (López 1990: 170 y ss ) de Medusa (Kramer 2011: 193-205 y 155-157). También tenemos el mosaico de Sagunto de Dirce, datado en el siglo II y es el primer mosaico con tema mitológico en el conventus tarraconense. La misma composición (Arreres 1989: 264) en blanco y negro se repite en un mosaico de Écija y en la Bética, ya del Bajo Imperio.

Casi todos los mosaicos de la llamada Casa del Mitreo, en la capital de la Lusitania, Emerita Augusta, están fabricados en blanco y negro, pero ya se introducen algunas tonalidades de color en los cántaros y en los delfines. Este mismo fenómeno reaparece en el mosaico de peces, descubierto en la Plaza de la Corredera de Córdoba, capital de la Bética (Monteagudo 2002: 595-626).

Este mismo hecho se documenta en el mosaico adornado con la cabeza de Medusa (Vazquez 2012: 69-82) de Carmena, en la Bética, o en el firmado por Seleucus de Mérida y en el de Neptuno de Itálica, con Neptuno marchando sobre las olas en un carro tirado por hipocampo, entre peces y monstruos marinos, con orla decorada con las luchas de los pigmeos y de grullas. El número de mosaicos hispanos en blanco y negro es bajo en la musivaria hispana.

En los mosaicos polícromos, se rompe mediante el color el efecto plano que producen en el observador los pavimentos en blanco y negro. Hay muchos que tienen decoración geométrica como peltas, estrellas, rosetas, nudos de Salomón, cruces de Malta, florones, roleos, guirnaldas, etc.; otros tienen bustos o figuras y los más importantes para nuestro tema son los que contienen composiciones decorativas que en su mayoría están sacadas de la mitología. En la provincia de Hispania tenemos desde representaciones de los dioses hasta las de las cuatro estaciones o las relativas al tiempo. Uno de los ejemplos más característicos es el del mosaico encontrado en Itálica que tiene temática de tipo astrológico con la representación de los planetas y los días de la semana. En cambio, un pavimento de Hellín (Sogorb 1987: 21 y ss) está adornado con las estaciones y los meses del año. Una de las provincias (Avilés 1941: 442-443) donde más se desarrollo el pavimento en blanco y negro fue la Tarraconense, aunque éste fue contemporáneo del pavimento en blanco y negro, cuyo uso no desapareció, como lo prueban mosaicos descubiertos en Tarraco y en Barcino. 
También abundan las representaciones(Kramer 2011: 193-205 y 155-157 ) de las personificaciones de los dioses. Un ejemplo de ello son los dos mosaicos como el Cosmogónico de Mérida (Quet 1968, 1981: 97-107, Quet 1979: 5-103) y el de Polifemo y Galatea de Córdoba. Mosaicos cuya iconografía desarrollaremos más adelante.

Además se han señalado en los temáticos paralelos con un mosaico de Chebba, Philippópolis, en Siria, datado en la segunda mitad del siglo III, en el que están presentes ya los frutos, Geogia, la agricultura, Triptolemo y en el registro superior dos putti, los cuatro vientos, el Notus, el Eurus, el Zephyr y el Bóreas. A este mosaico se ha dado una interpretación neoplatónica de la época de Pío tino, relativo al tiempo absoluto, Aión, y al tiempo relativo, Cronos. El mosaico de Polifemo y Galatea de Córdoba se fecha en torno al 200. Sigue un modelo pictórico de finales del helenismo (Brun 2004: 69-70).

Otro de los temas fundamentales en la minusvaria romana es el de la representación de temas mitológicos. A partir del siglo III se generalizan los grandes mosaicos polícromos de temas mitológicos entre los que destacan los pavimentos decorados con la pompa triunfal de Dionisos llevado en una carroza tirada por tigres acompañado de su amada Ariadna y seguido por un cortejo dionisiaco integrado por Sátiros y Bacantes, y por Pan, como en un mosaico de Ena, Zaragoza y en el de Torre de Palma en Portugal. Este punto es importante porque muchos temas mitológicos también contienen escenas con las estaciones y relativas al tiempo.

En época constantiniana se ponen de moda los mosaicos con cacerías y espectáculos. El más famoso es el que decora el anfiteatro de Centelles, Tarragona, con cacería de ciervos con la red, posible tumba del hijo de Constantino y fechado en torno a la mitad del siglo IV.

También son dignos de recordar, ya en el siglo IV, los mosaicos circenses de Barcelona y de Gerona y los cuadros con aurigas de vencedores de Mérida. Dos de ellos se encuentran entre un emblema dionisiaco, que prueba la vinculación de Dionisos con los juegos del circo y del anfiteatro. El mosaico de más calidad de los hallados en Hispania con escena de cacería es el hallado en la villa de las Tiendas, en Badajoz, en el que un cazador alancea a un jabalí. Podría tratarse del mito de Adonis. Probablemente el cazador representa al dueño de la casa, al igual que el descubierto en la villa del Ramalete, en Navarra (Bläzquez 1985: 55-56, №. 35, lám. 34, Pedraz 2004: 833, Figura 11), de nombre Dulcitius. En un segundo mosaico de Mérida, el cazador, de nombre Marianus, se halla de pie, junto a su caballo, de nombre Pafius, próximos a una cierva ya caída.

Durante el Bajo Imperio, Hispania, se cubrió de villas decoradas con espléndidos mosaicos. Como hemos comentado muchos de ellos eran de temas geométrico y otros decorados con escenas mitológicas de Teseo y el Minotauro, que adornan mosaicos de Torre de Palma. En fecha anterior, siglo II, en blanco y negro, se documenta ya en Pamplona y en Córdoba. Un unicum entre los mosaicos hispanos es el perdido pavimento de Osuna, en la Bética, con el mito de Arqueloo rodeado de Sirenas y de Ninfas.

Un mito, que alcanzó una gran aceptación entre los musivarios hispanos en el Bajo Imperio es el de Orfeo (Martínez 1990: 29-58) entre las fieras, con ejemplares en Caesaraugusta (Zaragoza), Santa María de los Barros y El Pesquero (Badajoz), Arneiro y Martín Gil (Portugal), y en Mérida. Orfeo estaba ya documentado en pavimentos del siglo II en Itálica y del siglo III en Mérida.

En época de Teodosio I, poco antes de las invasiones bárbaras que asolaron España entre los años 409-412, algunas villas se adornaron con espléndidos mosaicos, como los de La Olmeda (Palencia), con la leyenda de Aquiles en Skyros, acompañada de una espléndida galería de retratos. La villa de La Melena (Zaragoza) (Royo 1988-89, 1991: 209- 221, Galino 1992: 162-177), ha proporcionado un conjunto 
Mohamed Abouarab y Dayanna Carbonel / La iconografía y el concepto del tiempo...

de mosaicos de la más alta calidad artística. El principal representa las bodas de Cadmo y Harmonía, acompañados de los dioses olímpicos.

En cuadros, que rodean la escena central, se encuentran Antíope y sus hijos, la coronación de Antíope por estos y Antíope, Dirce e Ismeno. La villa de Carranque ha dado espléndidos mosaicos de un estilo muy original y refinado. Los mitos (Monteaguado 1998: 38-51, Monteaguado 2006: 285) representados son los de Hylas (Amigues 2002: 363-379), las Ninfas, Venus (Bayet 1956: 162 y ss.; BALIL 1985: 203 y ss.; Pedraz 1994: 393- 394) y Adonis. Aquiles y Briseida, leyenda que se repite en el mosaico de Mérida con los siete sabios de Grecia, baño de Diana, Príamo metamorfoseándose en Morera, mientras Tisbe huye de la leona y el caballo asediando a Amemone.

Algunos mosaicos del Bajo Imperio son obra, muy probablemente, de artesanos procedentes del Oriente, pues llevan letreros en griego, como el de tema homérico hallado en Cabezón de Pisuerga (Valladolid) y el citado de los siete sabios de Grecia de Mérida. Se ha señalado en los mosaicos hispanos del Bajo Imperio un fuerte influjo africano; en otros predomina el Oriente.

Uno de los mosaicos más originales de todos los aparecidos en Hispania y en todo el Imperio se halla en una villa de Fuente Álamo, en Puente Genil (Córdoba), fechado en el siglo IV. Va decorado con la lucha de los pigmeos y las grullas, con letreros sobre los personajes. Otro pavimento está decorado con figuras del Nilo, de un hipopótamo y de una zancuda. El estilo de las figuras es muy simple y el color oscuro. El tema está sacado de la comedia popular.

Al final de la Antigüedad, al igual que en otras regiones periféricas del Imperio, se detecta la descomposición de las formas artísticas clásicas, como en el dionisíaco de Alcalá de Henares; en el del taller de Annius Ponius de Mérida, también dionisíaco, ya bajo el impacto del arte oriental, datado en torno al 400; en el de Santisteban del Puerto (Jaén), con mito dionisíaco y con la lucha entre Apolo y Marsias y en el de Estrada (Zaragoza), con verso de Virgilio. Estos dos últimos son de un gran barbarismo en su estilo.

\section{Estilo e iconografía}

La Iconografía es la descripción del tema o asunto representado en imágenes artísticas recreando una simbología y los atributos que identifican a los personajes representados. Las iconografía de los calendarios son variables tenemos representaciones desde las estaciones del año hasta los meses y cada una de ellas evoluciona con el tiempo. Las personificaciones, pueden aparecer representadas asociadas, a temas relativos a la mitología romana, o solas. En la minusvalía romana, uno de los ejemplos que tenemos de representación de estaciones asociadas a alguna temática es un espléndido mosaico AD segundo siglo de Palencia que representa la Gorgona Medusa y las cuatro estaciones. La máscara de Medusa y las imágenes de las cuatro estaciones están rodeados de aves, lobos marinos y caballitos de mar. Ellos simbolizan la fertilidad y la evolución armónica del año. Mosaic of Medusa and the seasons, ca. AD 167-200, encontrado en Palencia, National Archaeological Museum of Spain, Madrid. (Imagen Medusa figuras 8 y 9 )

Medusa era una imagen popular en muchos hogares romanos, ya que se pensó que su habilidad para convertir a la gente en piedra sería alejar a los malhechores y equivocadas.

Otro mosaico de Hispania representa el genio del Año. Celebra sus atributos, una cornucopia (cuerno de la abundancia) y la serpiente. El genio del año favoreció el paso de las estaciones y las cosechas. Genios eran vistos como espíritus protectores, que protegían la casa y sus habitantes. 


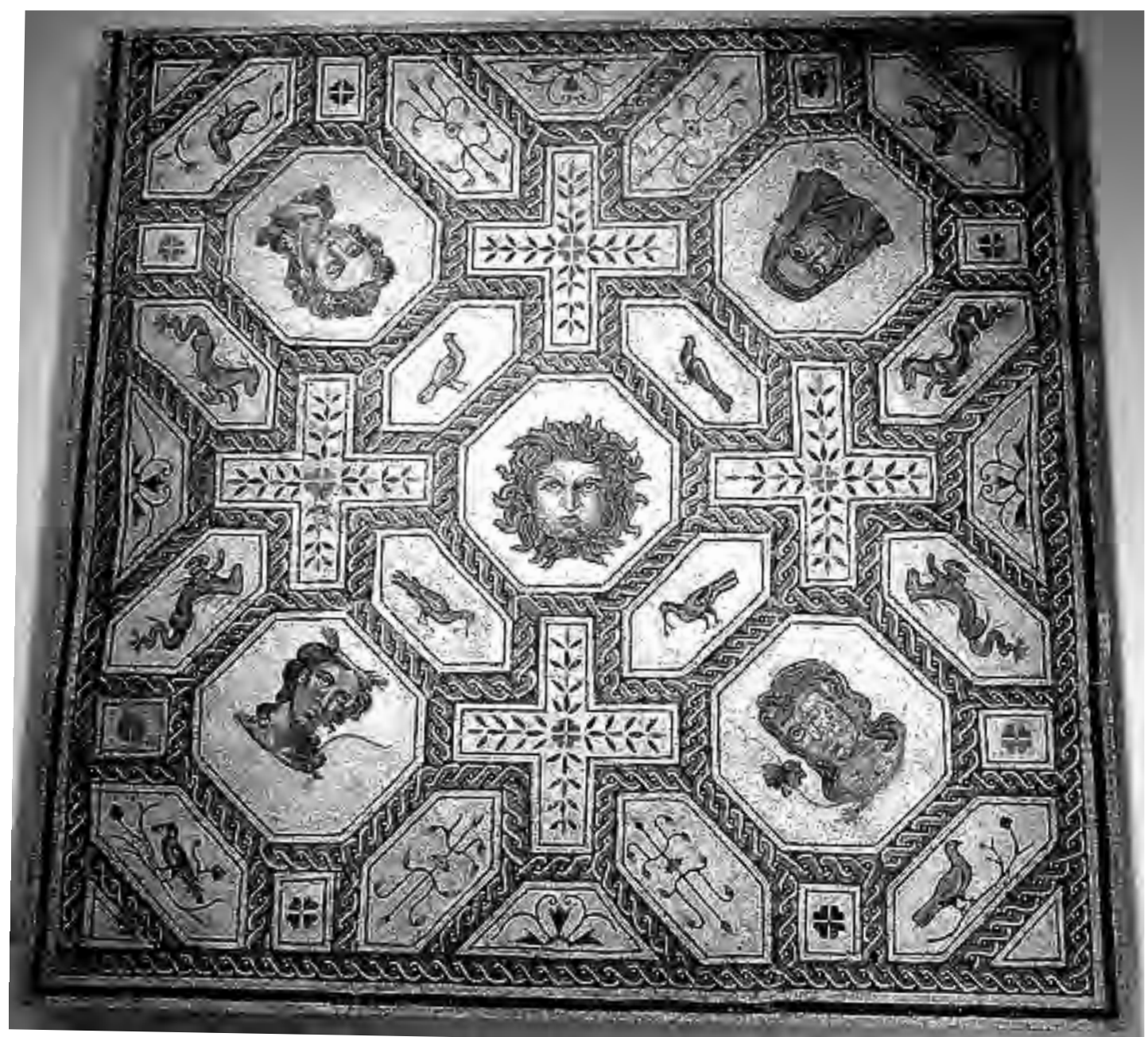

Figura 8. Mosaico de la Medusa y las estaciones del año, ca. AD 167-200, que se encuentra en Palencia, Museo Arqueológico Nacional de España, Madrid

Junto a este patio se halla el mosaico que da nombre a la casa. Dispuestos en un círculo en torno a Venus que corresponde al viernes se hallan: Selene o luna, lunes; Marte, martes; Mercurio, miércoles; Júpiter, jueves; Saturno, sábado; Helios o Sol, domingo. (Figuras 11 y 12)

En el lado opuesto (Parladé 1934: 7-8), con respecto a estos edificios, el Cardo Máximo, es la Casa del Planetario (Hidalgo 1999: 82-83), que se extendió a cerca de 1.600 metros cuadrados, ocupando la mitad occidental de un bloque. Dada la similitud de características, se piensa que como la Casa de los Pájaros, estaba destinado para el liderazgo de la ciudad.

En su interior se mantiene hasta nuestros días un mosaico del siglo II. AD, representando a los siete dioses planetarios que gobernaron el universo, y que, de acuerdo con el calendario romano de la semana tras la introducción por Constantino, dio su nombre a la actualidad: la Luna, Marte, Mercurio, Júpiter, Venus, Saturno dom es decir, un mosaico representa a los dioses que llevan el nombre de los días de la semana. Dispuestos en un círculo en torno a Venus que corresponde al viernes se hallan: 
Mohamed Abouarab y Dayanna Carbonel / La iconografía y el concepto del tiempo...

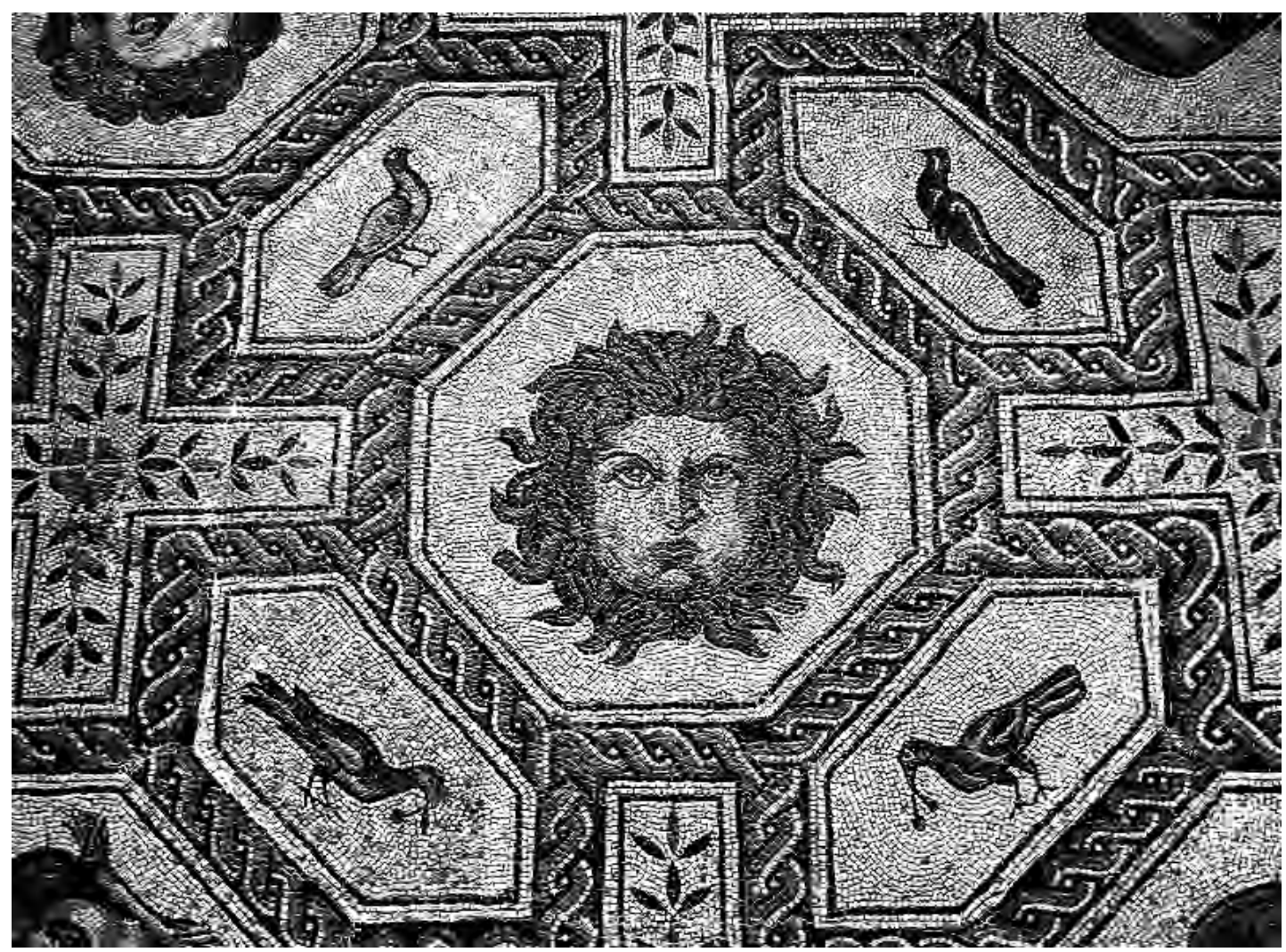

Figura 9. Detalle del mosaico de la Medusa y las estaciones del año, ca. AD 167-200, que se encuentra en Palencia, Museo Arqueológico Nacional de España, Madrid

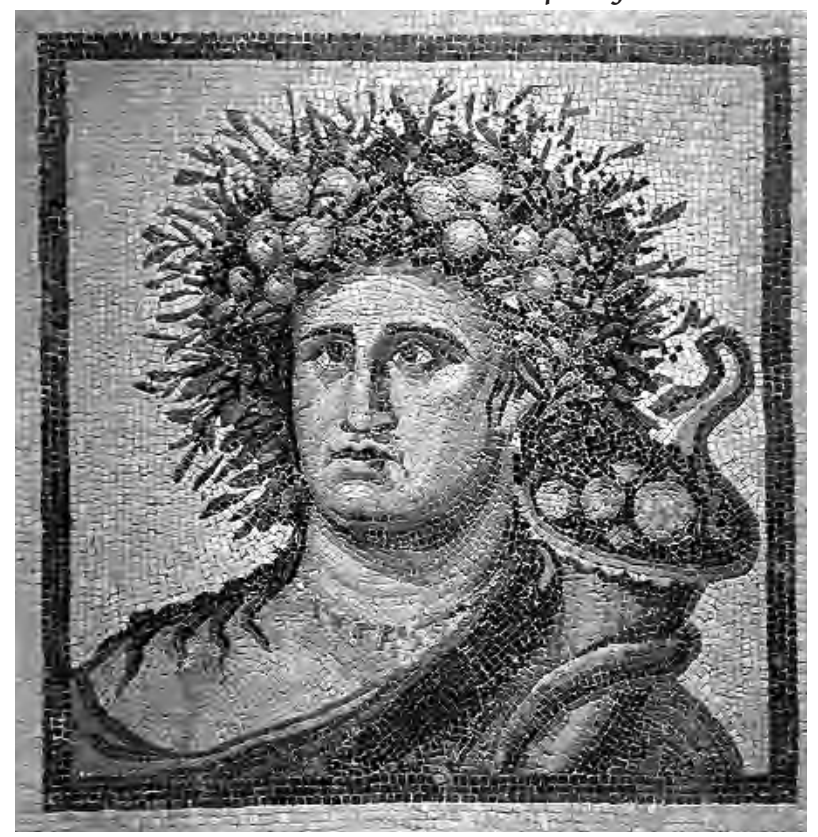

Selene o luna, lunes; Marte, martes; Mercurio, miércoles; Júpiter, jueves; Saturno, sábado; Helios o Sol, domingo.

Así, en el centro encontramos a Venus (diosa asociada al viernes), y rodeando su hexágono podemos ver a Saturno (sábado), el Sol (domingo), la Luna (Lunes), Marte (martes), Mercurio (miércoles), y Júpiter (jueves).

Los mosaicos eran un elemento decorativo y utilitario dentro de los recintos habitacionales. Teniendo varios estilos resaltantes, entre ellos el musivario el cual opta por representar en un círculo central de la diosa Venus (dies veneris),

Figura 10. Mosaico con el genio del Año, del siglo segundo dC tarde, que se encuentra en Aranjuez Museo Arqueológico Nacional de España, Madrid 


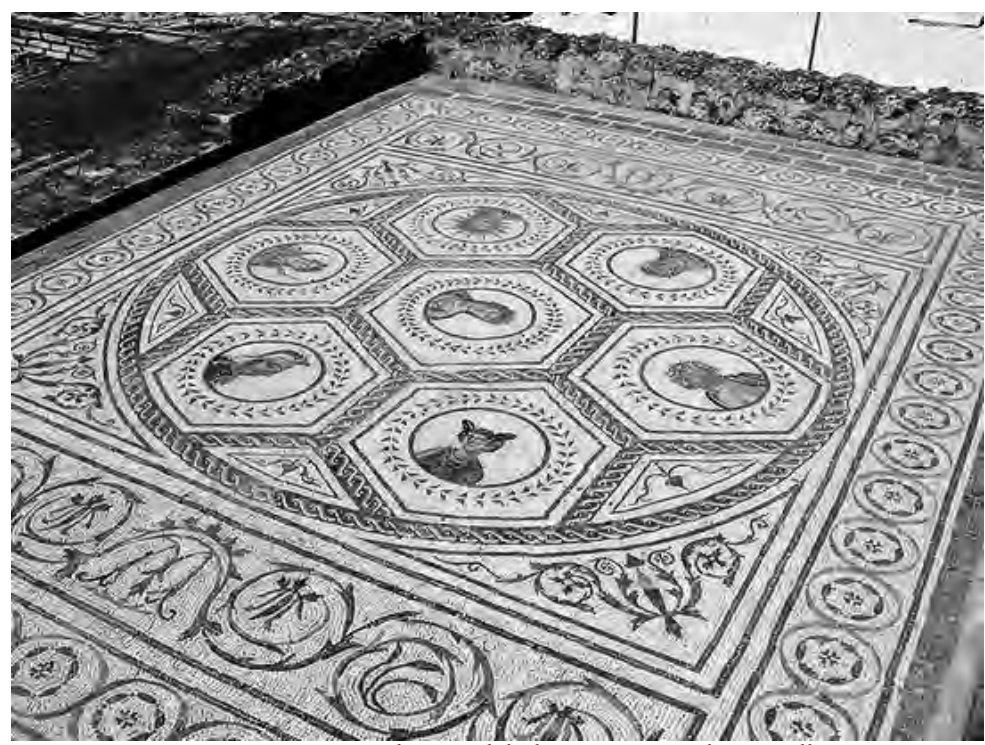

Figura 11. Mosaico Romano de Casa del Planetario en Itálica Sevilla, España http://www.romanoimpero.com/2014/11/italica-spagna.html diosa romana relacionada principalmente con el amor, la belleza y la fertilidad, pero también al último día de la semana. La secuencia se extendía de la siguiente manera: El dios saturno (dies saturni o sábado), la Luna (dies lunae o lunes), el dios Marte (die marti o martes), el dios Mercurio (dies mercurri o miércoles) y finalmente el dios Júpiter (dies iovis o jueves).

Sin embargo, dos mil años antes el Musivario Romano empleaba pequeñas cajas de teselas de colores y bocetos previos a la elaboración. Para muestra de ello fue encontra-

do en la Región Italica con representaciones de los días de la semana. De esta manera se iba abriendo paso al mundo Romano frente a la visión tradicional del calendario usado desde siglos anteriores

La siguiente imagen muestra un hebdomadario ${ }^{47}$ completo, en el cual cada día de la semana era asociado a un astro, manteniéndose dicha asociación hasta nuestros días.

Pudiéramos creer que el artista de nombre desconocido, situó a Venus en el centro de la composición debido a que el viernes era el último día de la semana para los antiguos romanos. Disposiciones y nombres -salvando las lógicas variaciones- que seguimos utilizando actualmente.

Figura 12. Mosaico Romano de Casa de Planetario en Itálica Sevilla, España, Primera mitad del siglo II d.C. http://www.engranajesculturales.com/actividades/las-musas-de-italica/visita-las-musas-de-italica-mosaico-de-la-casa-del-pla-

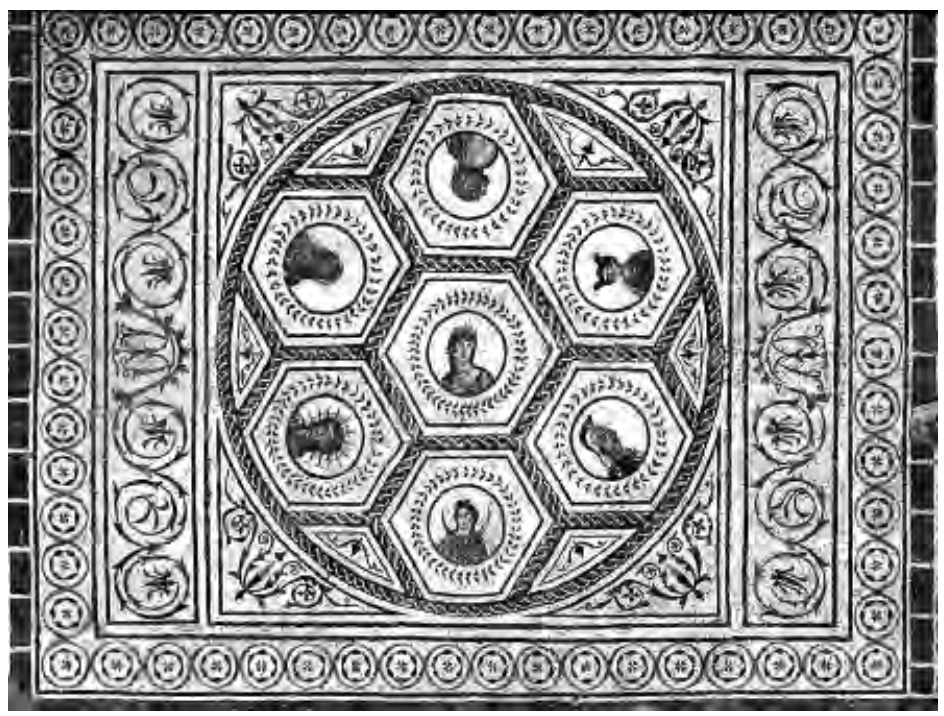

47. El Diccionario de la lengua española es la obra de referencia de la Academia. Heddomario: adj. Semanal. M. y f En los cabildos eclesiásticos y comunidades regulares, semanero, persona que se destina cada semana para oficiar en el coro o en el alta 
Mohamed Abouarab y Dayanna Carbonel / La iconografía y el concepto del tiempo...

\section{CONCLUSIÓN DEL ANÁLISIS HISTÓRICO-ARTÍSTICO}

La evolución de los mosaicos que en sus primeras fases tuvieron un fin decorativo y suntuoso pasando luego a tener una connotación utilitaria con los calendarios, hasta llegar a nuestros tiempos y convertirse en un elemento fundamental en nuestras vidas cotidianas. Ello nos lleva a reflexionar sobre los procesos de aculturación en el cual, las poblaciones Hispanas recepcionaron y asimilaron nuevos elementos culturales productos de la invasión Romana. En este sentido los sucesos históricos sufridos en la región Ibérica dan como resultado al enriquecimiento cultural que se gesta en siete siglos de dominación. Llegando a complejizarse hacia otros aspectos como el sincretismo, mestizaje, transculturización e hibridación.

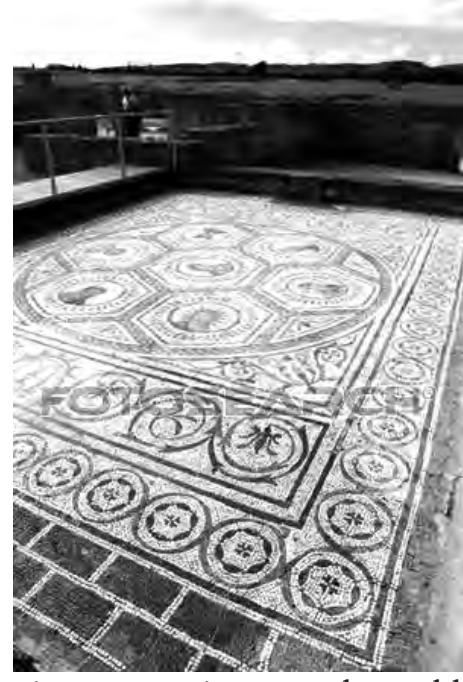

Figura 13. Mosaico Romano de Casa del Planetario en, Itálica Sevilla, España

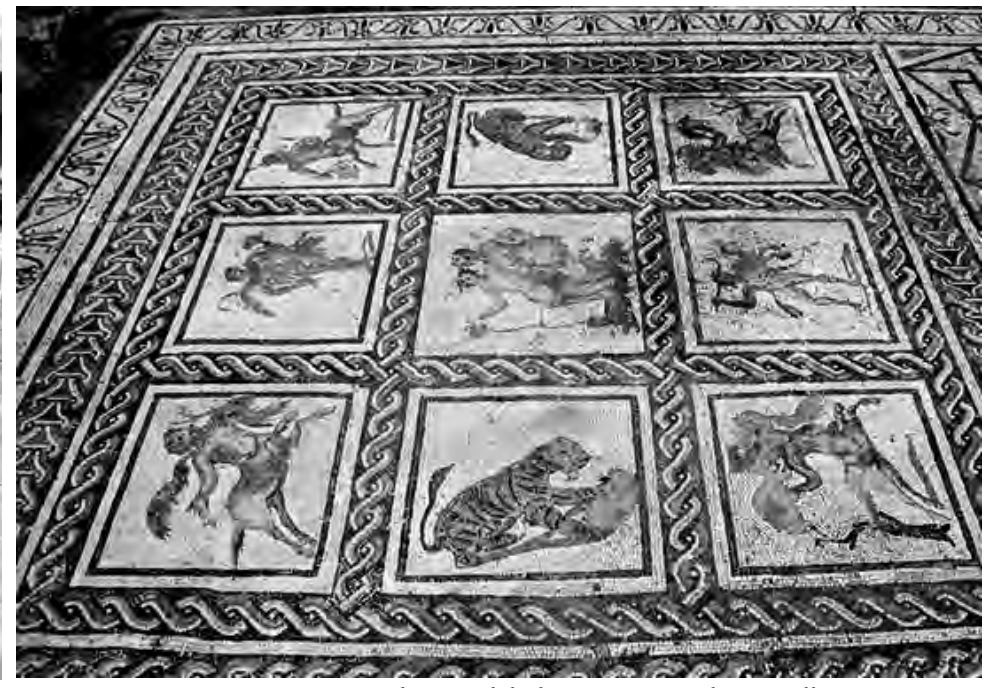

Figura 14. Mosaico Romano de Casa del Planetario en Itálica Sevilla, España http://www.romanoimpero.com/2014/11/italica-spagna.html

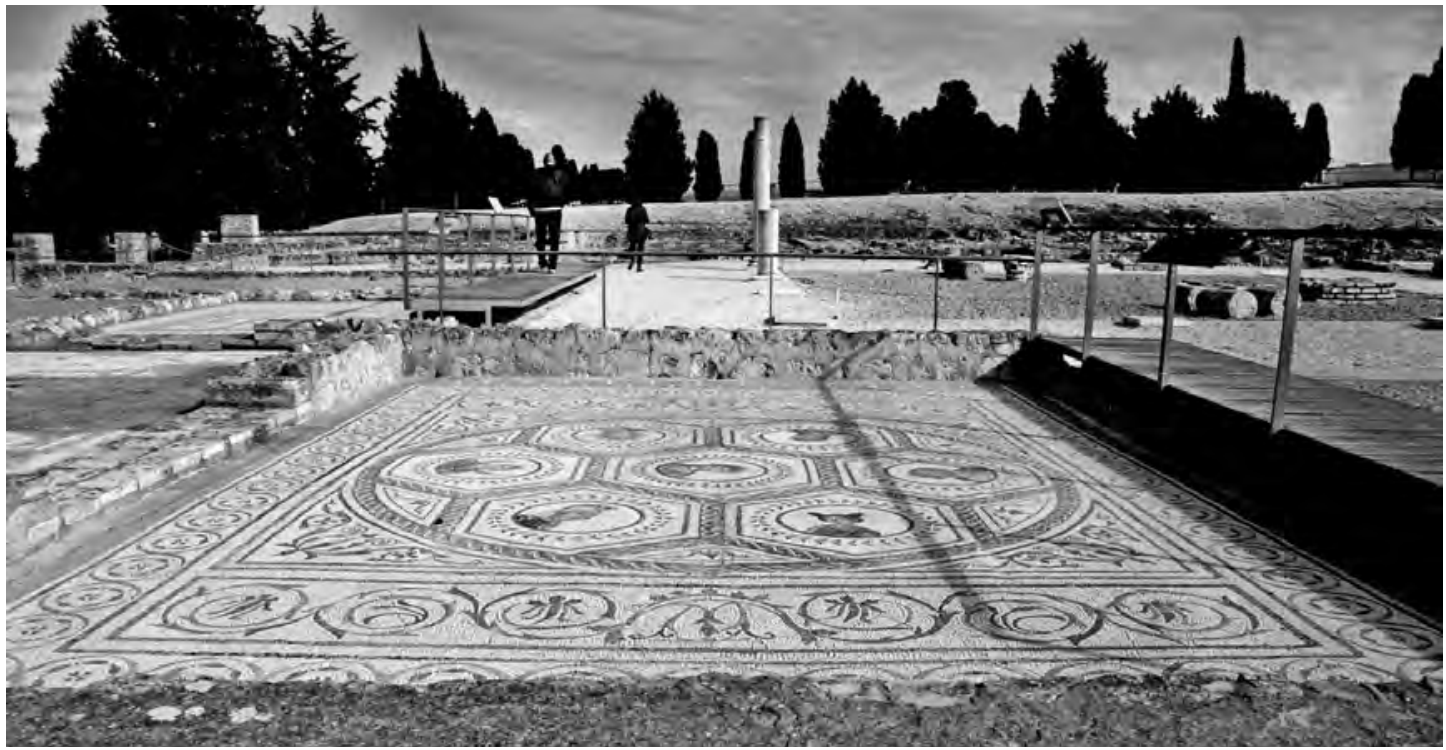

Figura 15. Vista general del Mosaico 


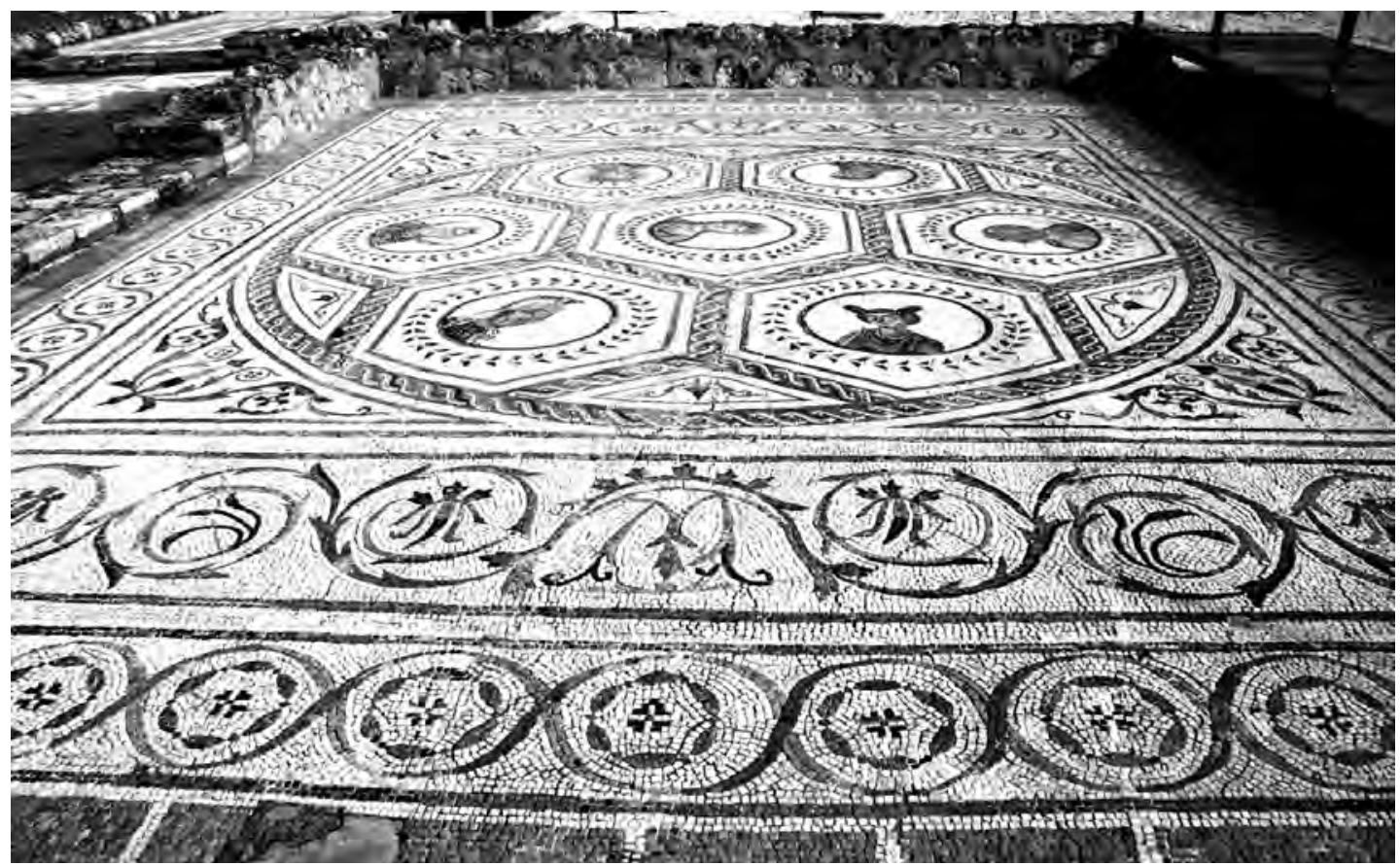

Figura 16. Vista del Mosaico

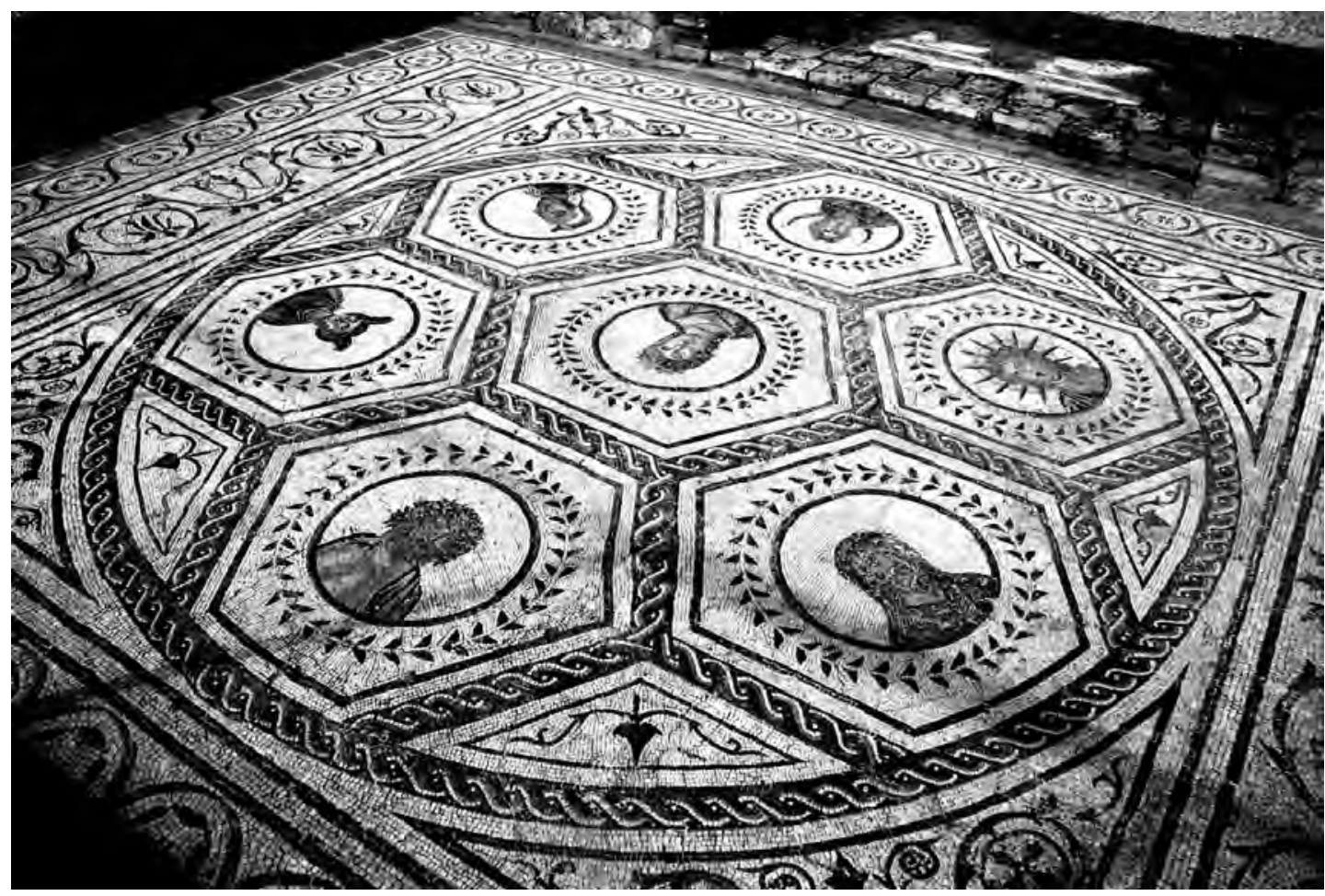

Figura 17. Rosa de los dioses 
Mohamed Abouarab y Dayanna Carbonel / La iconografía y el concepto del tiempo...

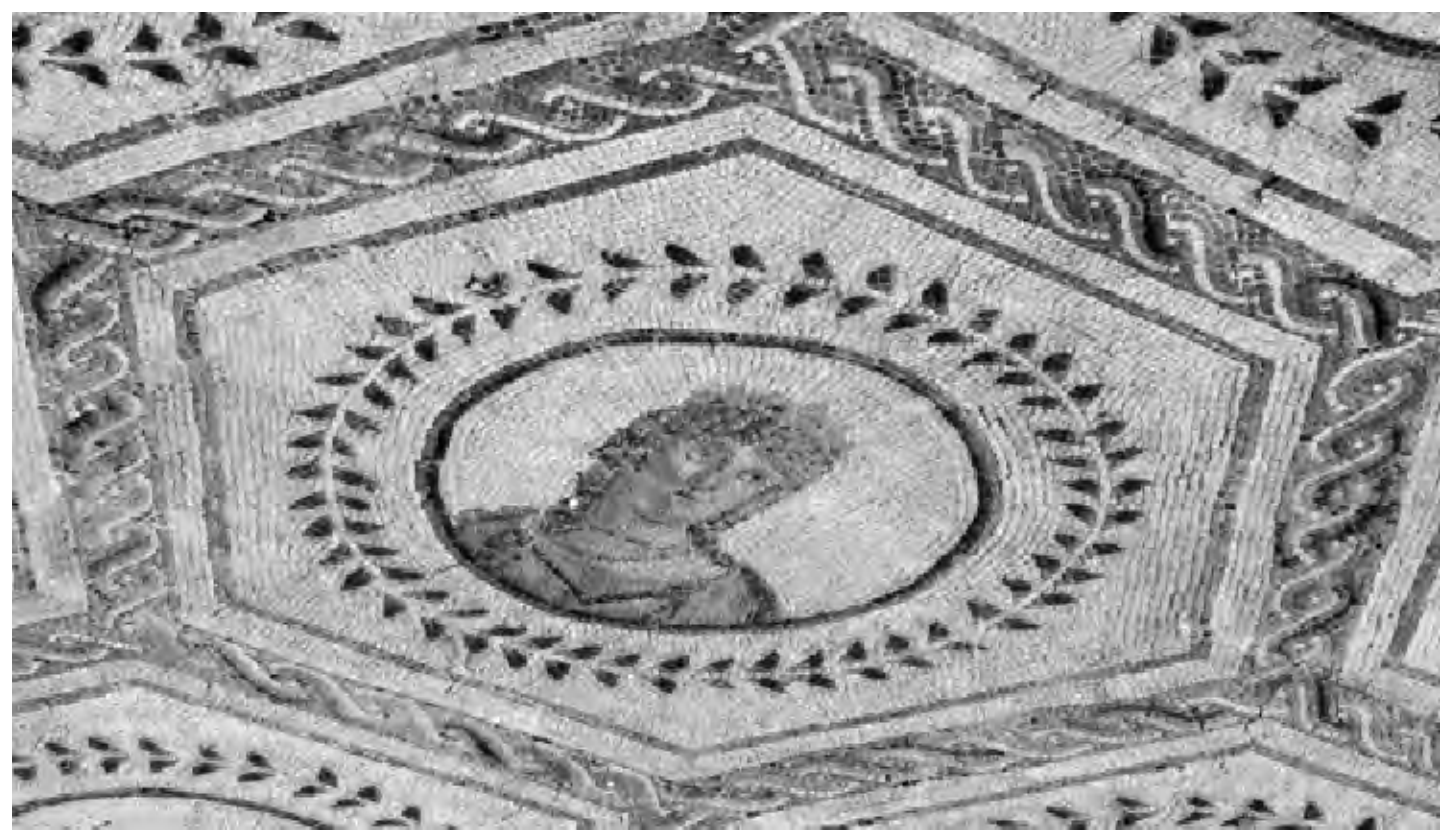

Figuraura 18. Venus, detalle de la representación del día del viernes

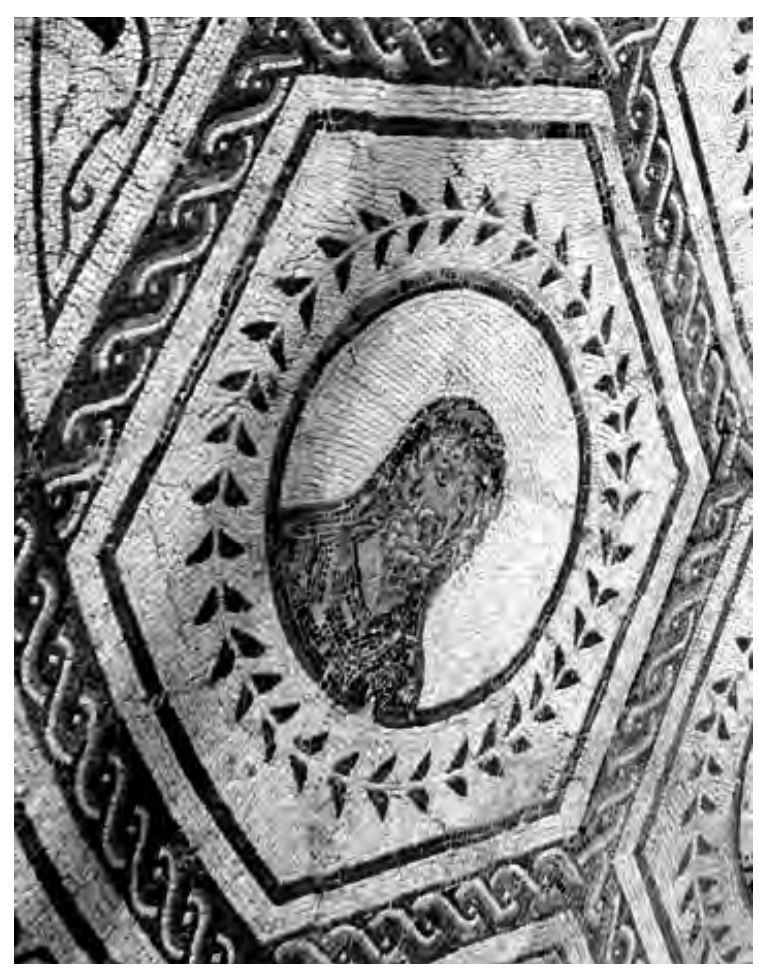

Figuraura 19. Saturno, detalle de la representación del día sábado

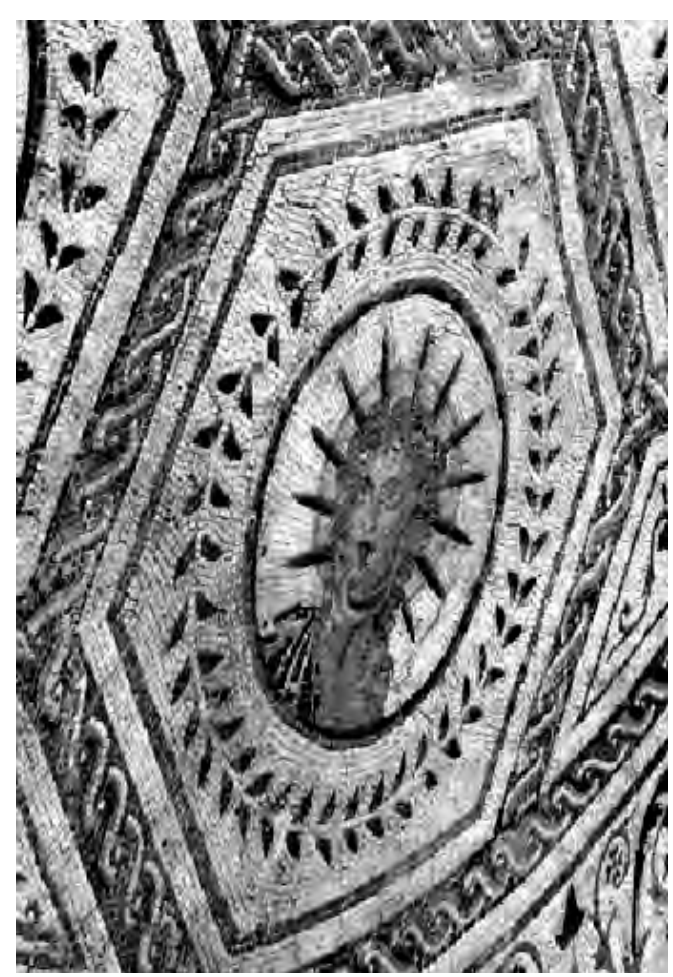

Figuraura 20. El Sol, detalle de la representación del día domingo
159 


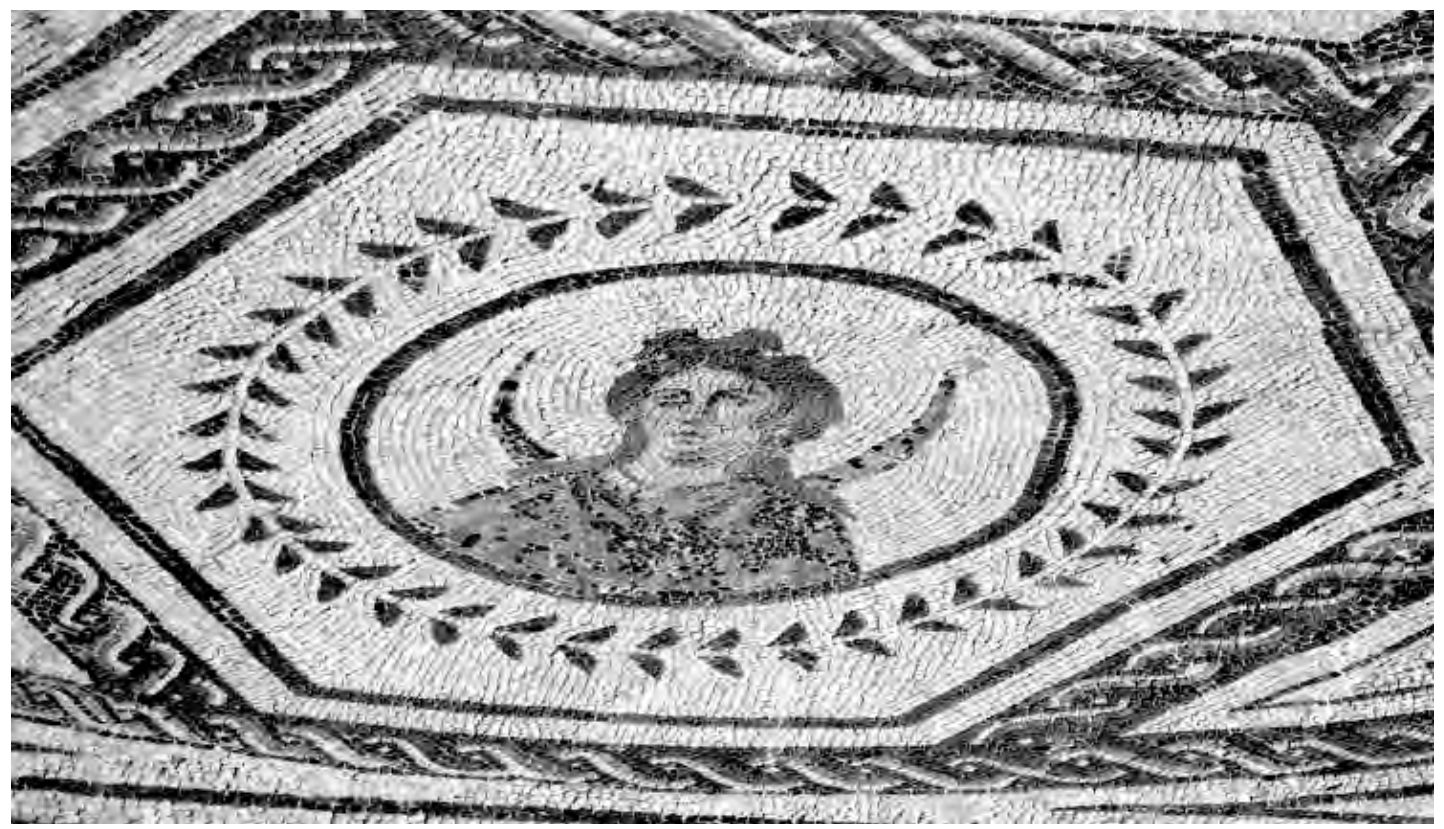

Figuraura 21. La Luna, detalle de la representación del día lunes

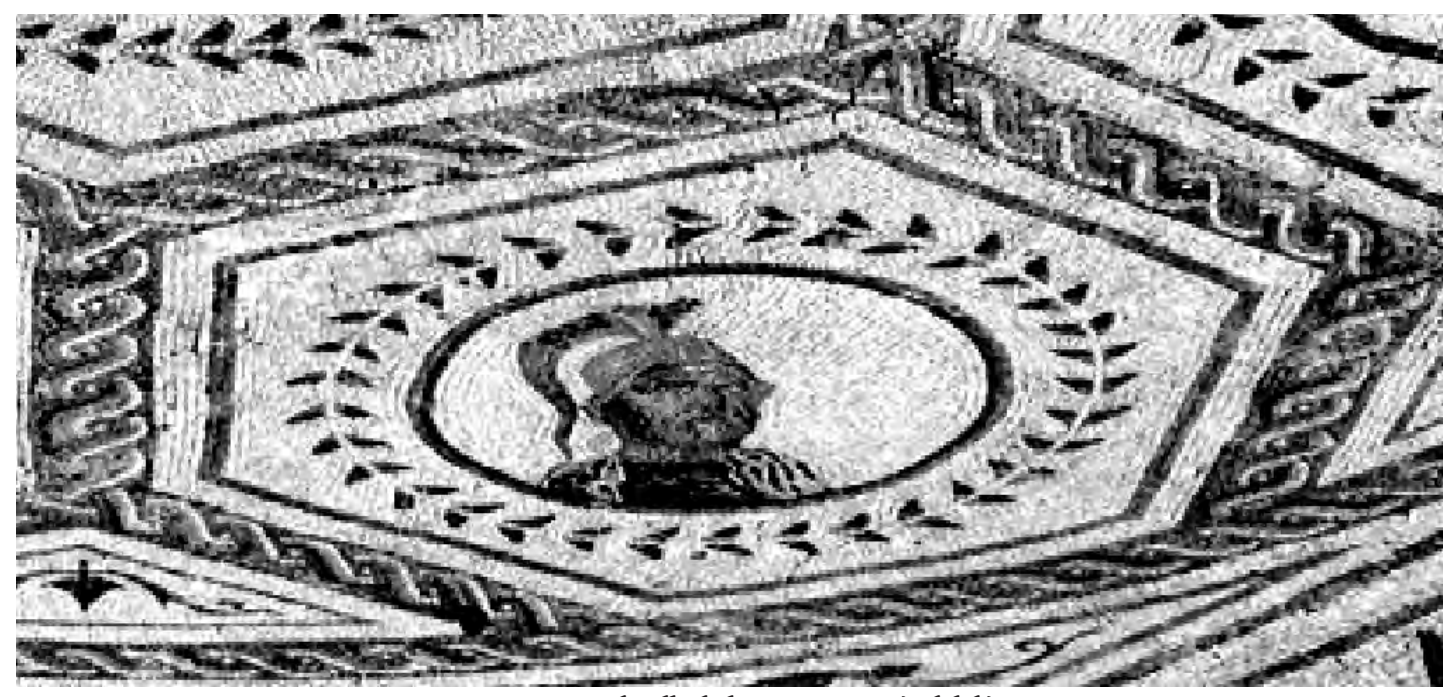

Figuraura 22. Marte, detalle de la representación del día martes 
Mohamed Abouarab y Dayanna Carbonel / La iconografía y el concepto del tiempo...

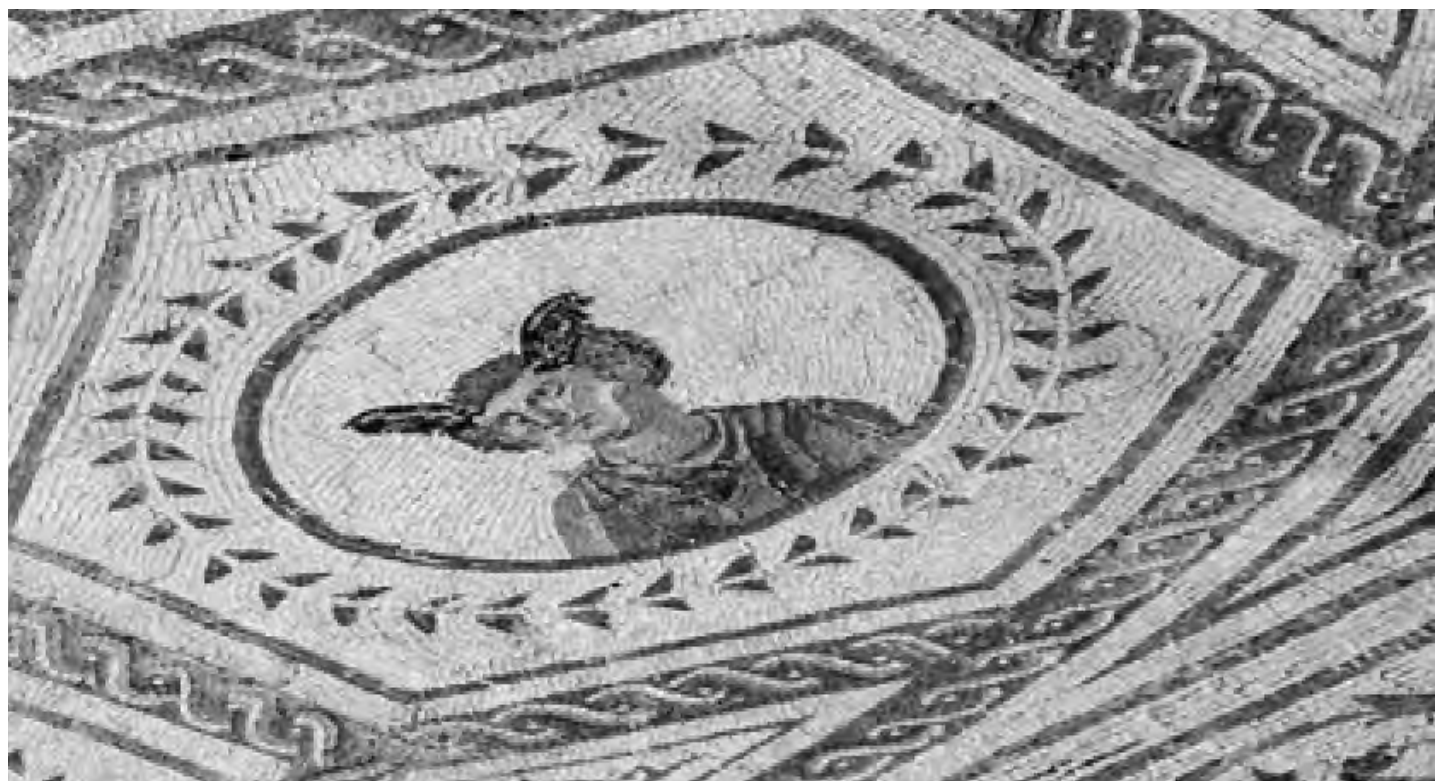

Figura 23. Mercurio, detalle de la representación del día del martes

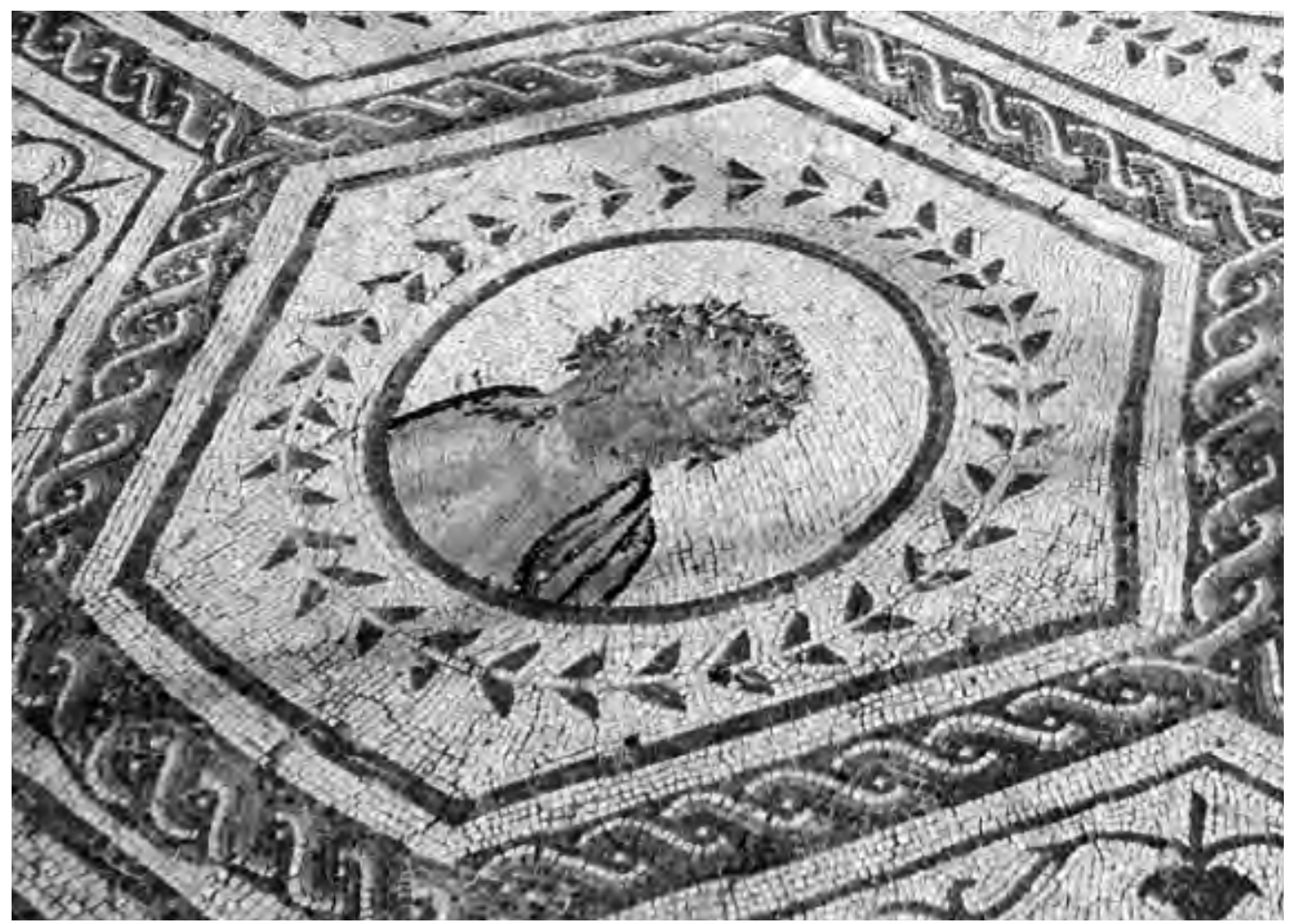

Figura 24. Júpiter, detalle de la representación del día del jueves 





Mohamed Abouarab y Dayanna Carbonel / La iconografía y el concepto del tiempo...

\section{BiBLIOGRAFÍA}

ÁLVAREZ MARTÍNEZ, J. M.,

1990 La icnografia de Orfeo en los mosacicos hispanoromanos, en Mosaicos romanos: estudios sobre iconografía. Actas del Homenaje "in memoriam" de Alberto Balil, Guadalajara, pp. 29-58.

1990 La iconografía de Orfeo en los mosaicos hispanorromanos, Annalisa Marzano, Roman Villas in Central Italy: A Social and Economic History, Columbia University Press, 2007, pag. 297.

ARASA, Ferrán

1999 La romanización: cambio cultural en el mundo ibérico en los siglos XX-I a.C., en Rodrigo de Balbín Behrmann y Primitiva Bueno Ramírez (ed.): II Congreso de Arqueología Peninsular. Tomo IV. Arqueología Romana y Medieval, Madrid, Universidad de Alcalá, Fundación Rei Afonso Enriques, pp. 65-73.

AMIGUES, Suzanne

2002 De la botanique à la poésie dans les Idylles de Théocrite, Études de botanique antique, Mémoires de l'Académie des inscriptions et Belles-Lettres 25, Paris, de Boccard, 2002, pp.363-379

BALIL, Alberto

1985 Venus y Adonis. Mosaicos romanos. Actas de la I. Mesa Redondo Hispano-Francesa sobre Mosaicos Romanos. Madrid 1985, p. 203 y ss.

BAYET, Jean

1956 La religión romaine, histoire politique et psychologique, Petite Biblioteque Payot, París, p. 162 y ss.

BLANCHET A.

1909 Inventaire des mosaïques de la Gaule, II, París, 1909, número 734, p. 10.

BLANCO, A.

1978 Mosaicos romanos de Itálica. Corpus de Mosaicos de España II, Madrid, 8, 32-34, Figura 2, láms. pp. 20-27.

BLÄZQUEZ, J.M. y MEZQUIRIZ, M.A

1985 Mosaicos romanos de Navarra, CMRE VII, Madrid, pp. 55-56, ํo. 35, lám. 34.

BLÁZQUEZ, J. M.,

1993 Influjos africanos en los mosaicos hispanos, Mosaicos romanos de España, pp. 70-92.

BRUN, J.-P.

2004 Archéologie du vin et d'huile. De la préhistoire à l'époque hellénistique, Paris, 69-70.

BLÁZQUEZ MARTÍNEZ, J.M ${ }^{a}$

1981 Mosaicos romanos de Córdoba, Jaén y Málaga. Corpus de Mosaicos Romanos de España. Fascículo III. Consejo Superior de Investigaciones Científicas. Madrid.

1982 Mosaicos romanos de Sevilla, Granada, Cádiz y Murcia. Corpus de Mosaicos Romanos de Espa$\tilde{n} a$. Fascículo IV. Consejo Superior de Investigaciones Científicas. Madrid. 
1984 Mosaicos báquicos de la Península Ibérica. Archivo Español de Arqueología 57. 69-95.

1998 Mosaicos Sirios de la Colección Villa Real, Madrid. Real Academia de la Historia. XV. 477-494. BLÁZQUEZ MARTÍNEZ, J.Mำ, LÓPEZ MONTEAGUDO, G, NEIRA JIMÉNEZ, Mํa.L. SAN NICOLÁS PEDRAZ, Ma.P.,

1986 Hallazgos de mosaicos romanos en Beas de Segura (Jaén). Archivo Español de Arqueología. Vol. 59. 227-232.

1989 Mosaicos Romanos de Lérida y Albacete. Corpus de Mosaicos Romanos de España. Fascículo VIII. Consejo Superior de Investigaciones Científicas. Madrid.

BLANCO FREIJEIRO, A

1978 Mosaicos romanos de Mérida. Corpus de Mosaicos Romanos de España. Fascículo I. Consejo Superior de Investigaciones Científicas. Madrid.

1978 Mosaicos romanos de Itálica (I). Corpus de Mosaicos Romanos de España. Fascículo II. Consejo Superior de Investigaciones Científicas. Madrid.

CANTO, A. $\mathrm{M}^{\mathrm{a}}$

1976 El mosaico del Nacimiento de Venus de Itálica. Habis № 7, 293-338.

CARRASCOSA MOLINER, B. y PASÍES OVIEDO, T.

2004 La conservación y restauración del mosaico. Universidad Politécnica de Valencia. Valencia.

DE RUEDA ROIGÉ, F.J.

2002-2003 El mosaico de las Estaciones de la Casa de las Hilas, en Itálica. Nueva interpretación iconográfica. Locvs amoenvs 6. 7-20.

DOSI, A. - SCHNELL, F.

1992 Spazio e tempo. Museo della Civilta Romana 14, Ill. 42. p. 61

1992 Vita e costumi dei Romani antichi, in Museo della Civiltà Romana, Spazio e Tempo, vol.14, ed. Quasar, Roma.pp. 65

DUNBABIN, K.M.D.

1978 The Mosaics of Roman North Africa. Studies in Iconography and Patronage, Oxford, p. 17, lám. 96

EGBERT, James Chidester

1896 Introduction to the Study of Latin Inscriptions, New York, 1896, p. 368

FERNÁNDEZ DE AVILÉS, August

1941 Un nuevo mosaico descubierto en Hellín (Albacete) en Archivo español de Arqueología, 44 (1941), pp. 442-443.

FIORI, C. y VANDINI, M.

2002 Teoria e tecniche per la conservazione del mosaico. Il Prato Casa Editrice. Padua. 
Mohamed Abouarab y Dayanna Carbonel / La iconografía y el concepto del tiempo...

\section{FERNÁNDEZ-GALIANO RUIZ, D.}

1982 Nuevas interpretaciones iconográficas sobre mosaicos hispanorromanos Museos, 1, pp. 1727. (1984): El triunfo de Dionisos en mosaicos hispanorromanos. Archivo Español de Arqueología, vol. 57, pp. 97-11

1982 Nuevas interpretaciones iconográficas sobre mosaicos hispanorromanos, Museos, 1, p. 17.

1984 El triunfo de Dionisos en mosaicos hispanorromanos. Archivo Español de Arqueología, vol. 57, pp. 97-11

1992 Cadmo y Harmonía: imagen, mito y arqueología, Journal of Roman Archaeology 5, pp. 162-177.

FERNANDEZ GÓMEZ, F.,

1984 Sevilla. Excavaciones de urgencia, Arqueología 83. Memoria de las excavaciones programadas en el año 1983, pp. 60-62.

GARCIA SANDOVAL, J.

2004 Musivaria: arte y técnica. Taller de mosaicos romanos, (en línea) Revista de Arqueomurcia № 2, pp. 1-88.

GARCIA SANDOVAL, J., PLAZA SANTIAGO, R. y FERANDEZ DIAZ, A.

2004 La musicalización de las pinturas romanas de La Quintilla (Lorca): restauración y montaje expositivo, AlbercA, 2, Lorca, pp. 125-138.

\section{JÖRG RÜPKE}

2011 The Roman Calendar from Numa to Constantine: Time, History, and the Fasti. (Translated by David M. B. Richardson; originally published 1995, Chichester; Malden, MA: Wiley-Blackwell, Pp. vi, 226.

JOHNSON, Van L.

1960 Natalis Urbis e Principium anni, Transactions and Proceedings of the American Philological Association, 91, pp. 110.

KRAMER, M.

2011 Aspectos de la feminidad en las representaciones de la primavera y el invierno, en: Neira, L. (Coord. y Ed.), Representaciones de mujeres en los mosaicos romanos y su impacto en el imaginario de estereotipos femeninos, Madrid, Ediciones CVG, PP. 193-205 y 155-157.

LAFAYE, G.

1909 Inventaire des mosaiques de la Gaule, I, Paris, N 187, p. 43.

LAGÓSTENA BARRIOS, L.

1996 Alfarería romana en la Bahía de Cádiz. Universidad de Cádiz. Cádiz

LAVADO FLORIDO, M $M^{\mathrm{a}} \cdot \mathrm{L}$.

2010 Memoria final de la intervención arqueológica llevada a cabo en proyecto de la duplicación de la carretera N-IV. Tramo final: variante Puerto Real- Tres Caminos del P.K. 671,8. Cádiz. Anuario de Arqueología de Andalucía 2004.II. Junta de Andalucía, Consejería de Cultura. Sevilla. 99-144. 
2004 El complejo industrial de Puente Melchor: el centro productor, la organización del espacio y su área de influencia. Figuralinae Baeticae: talleres alfareros y producciones cerámicas en la Bética romana (ss. II a. C- VII d. C); actas del Congreso Internacional, Cádiz. Vol. 2. 4

LOPEZ, Aurora

1990 La mujer en la sátira romana. La mujer en el mundo Mediterráneo antiguo. Universidad de Granada 1990, p. 170 y ss.

LÓPEZ MONTEAGUDO, G.

1978 El simbolismo de la travesía marina en algunos mitos clásicos, Latomus MESLIN, M. L'Homme Romain - Des origines au Ier siècle de notre ère. Paris: Hachette, p. 55-74.

2001 Los mosaicos romanos de Écija (Sevilla). Particularidades iconográficas y estilísticas, La mosaïque gréco-romaine VIII, Actes du VIIIème Colloque inter-national pour l'étude de la mosaïque antique et médiévale, vol. II, pp 130-146.

2002 El impacto del comercio marítimo en tres ciudades del interior de la Bética, a través de los mosaicos, L'Africa romana XIV, Sassari 2000, Sassari, pp. 595-626.

2004 La musivaria romana en época de Trajano. Espacio, Tiempo y Forma. Serie II, Historia Antigua, t.15. 181-204.

2006 Lo provincial y lo original en los mosaicos romanos. Original versus provincial, en Homenaje a la profesora Pilar León Alonso, Córdoba, p. 285.

LÓPEZ MONTEAGUDO, G. y SAN NICOLÁS PEDRAZ, Mª.P.,

1995 El mito de Europa en los mosaicos hispano-romanos. Análisis iconográfico e interpretativo. Espacio, Tiempo y Forma. Serie II, Historia Antigua, t. 8. 383-438.

LÓPEZ MONTEAGUDO G. Y NEIRA JIMÉNEZ,

2010 Los mosaicos romanos, en Arte romano de la Bética, vol. III. Sevilla.

LUZÓN NOGUÉ, J.M.,

1988 La roseta de triángulos curvilíneos en el mosaico romano. Anejos de Gerión. I. Universidad Complutense. Madrid. 213-241.

MÉLIDA, J. R.

1935 El arte en España durante la época romana en Historia de España dirigida por R. Menéndez Pidal, II, Madrid, pp. 709-710.

MEZQUÍRIZ IRUJO, Mํ.A.,

2004 Los mosaicos de la villa romana de Liédena (Navarra). Príncipe de Viana. 327-359.

MENÉNDEZ PIDAL

1955 Historia de Espana, 11, p. 767 y SS., Figuras 537, 540-552.

MAÑAS ROMERO, I.,

2009 Pavimentos decorativos de Itálica. Una fuente para el estudio del desarrollo urbano de la ampliación adrianea. ROMVLA. № 8. Universidad Pablo de Olavide Sevilla. 179-198. 
Mohamed Abouarab y Dayanna Carbonel / La iconografía y el concepto del tiempo...

2011 Mosaicos Romanos de Itálica (II). Corpus de Mosaicos Romanos de España. Fascículo XIII. Consejo Superior de Investigaciones Científicas. Madrid.

NEIRA JIMÉNEZ, L.,

1998 Paralelos en la musivaria romana de Grecia e Hispania. A propósito de un mosaico de Alcolea del Río y un pavimento de Mitilene. Anales de Arqueología Cordobesa, 9. 223-246.

QUET, N. H.

1979 La mosaique cosmologique de Merida. Propositions de lecture, Coninbriga XVIII, pp. 5-103.

(1968): Aion, á propos d’une libre récent, Revue des Studes Anciennes, págs. 97-107.

1968, 1981, Aion, á propos d'une libre récent, Revue des Studes Anciennes, págs. 97-107.

PARRISH, David

1984 Season Mosaics of Roman North Africa, Roma, lám. 289. p. 133

PATRICH, Joseph

2011 Studies in the Archaeology and History of Caesarea Maritima, Brill, pag. 84, nota 53.

PLÁCIDO SUÁREZ, Domingo

2008 La ecúmene romana: espacios de integración y exclusión. Presentación, Studia Historica. Historia Antigua, núm. 26, pp. 15-20.

PANAGIOTOPOULOU, A.,

1994 Représentations de la Meduse dans les mosaiques de Gréce, VI CIMA, pp. 369-383.

PARLADÉ, A.

1934 Excavaciones en Itálica. Campañas de 1925 a 1932. Junta Superior del Tesoro Artístico, 127, 7-8.

REAL ACADEMIA DE LA LENGUA ESPAÑOLA.

2014 Diccionario de la lengua española. Edición 23.

RODRÍGUEZ FRADE, P.,

2006 Realización de soportes de montaje para la exposición en el Museo Histórico Municipal del mosaico de tema estacional de la Avda. Miguel de Cervantes, 35 (Écija). Astigi Vetus. Revista del Museo Histórico Municipal de Écija, 2. 149-154.

ROMERO, M., MAÑAS, I. y VARGAS, S.,

2006 Primeros resultados de las excavaciones realizadas en la Villa de la Estación (Antequera, Málaga). Archivo Español de Arqueología. Vol. 79. 239-258.

RASCÓN MARQUÉS, S., MÉNDEZ MADARIAGA, A. y SÁNCHEZ MONTES, A.L.,

1993 “El mosaico del Auriga de la villa romana de El Val (Alcalá de Henares, Madrid)”. Espacio, Tiempo y Forma. Serie I. Prehistoria y Arqueología, t.6. 303-342.

RODRÍGUEZ HIDALGO J.M

1999 Itálica arqueológica. Sevilla. 82-83. 
ROYO. J. I.

1991 Excavaciones en La Malena (Azuara, Zaragoza) 3ª campaña 1988, Arqueología Aragonesa 1988-89, 1991, págs. 209- 221;

RÜPKE, J.

2011 The Roman Calendar from Numa to Constantine. Time, History and Fasti, Wiley - Blackwell, 2011.

SÁNCHEZ ALBORNOZ, C.

1949 El proceso de romanización de España desde los Escipiones hasta Augusto, Anales de Historia Antigua y Medieval, 1949, p. 11.

SANDYS, John Edwin

1919 Latin Epigraphy: An Introduction to the Study of Latin Inscriptions, Cambridge University Press, 1919, pag. 174.

SAN NICOLÁS PEDRAZ, Mạ.P.,

1989 Mosaicos Romanos del Museo Arqueológico Nacional. Corpus de Mosaicos Romanos de España. Fascículo IX. Consejo Superior de Investigaciones Científicas. Madrid.

1993 Hallazgos de los mosaicos romanos en Hispania (1977-1987). Espacio, Tiempo y Forma. Serie II, Historia Antigua, t. 6. 221-296.

1994 La iconografia de Venus en los mosaicos Hispanos, VI CIMA, Guadalajara, C. M. Batalla, pp. 393-406.

1994 La iconografía de Venus en los mosaicos hispanos, VI Coloquio Internacional sobre Mosaico Antiguo (Palencia- Mérida 1990), Mérida 1994, pp. 393- 394.

1998 El mosaico romano en Hispania. Departamento Arqueología y Prehistoria. UNED. Madrid. 5788.

1991 Sobre el mosaico perdido de Galatea, Italica (Sevilla), Antigüedad y Cristianismo VIII, Murcia, Universidad de Murcia, pp. 531-540.

2004 Mosaicos hispano- romanos con representaciones de murallas, L'Africa Romana XV, p. 833, Figuraura 11.

SALZMAN, Michele Renee

1990 On Roman Time: The Codex Calendar of 354 and the Rhythms of Urban Life in Late Antiquity, University of California Press, pag. 170.

SANDYS, John Edwin

1919 Latin Epigraphy: An Introduction to the Study of Latin Inscriptions, Cambridge University Press, 1919, pag. 174

STANLEY PRICE, N.

1991 The Conservation of the Orpheus Mosaico at Paphos, Cyprus. Malibu. The Getty Conservation Institute-Oxford University Press. 
Mohamed Abouarab y Dayanna Carbonel / La iconografía y el concepto del tiempo...

TARACENA, Blas

1947 Arte romano, vol. 11 de Ars Hispaniae. Madrid, p. 160 y Figura 152.

1955 Arte romano, vol. 11 de Ars Hispaniae. Madrid, 1947, p. 160 y Figura 152. Historia de España) (Menéndez Pidal), 11, p. 767 y SS., Figuraura 537, 540-552.

SARTHOU CARRERES, C.

1989 Geografía general del Reino de Valencia: Provincia de Castellón. p.264. Barcelona. Ed. Alberto Martín. 1913; edició de la Caja de Ahorros y Monte de Piedad de Castellón. Sant Vicenç dels Horts (Barcelona). 1989.

1989 (Provincia de Valencia), vol. 11 (Geografia General del Reino de Valencia). Barcelona, s.a., p.554.

SOGORB, C.

1987 Los mosaicos de la villa romana de Hellín, Boletín del Museo Arqueología Nacional, Tomo V, № 1 y 2 , p. 21 y ss.

VERA REINA, M.

1991 Estudio sobre una serie musiva del foro cívico hispalense. Revista de Historia del Arte. № 3. 9-15.

VARGAS VÁZQUEZ, S.,

2009 Jugando con las imágenes: el juego de la geometría en la musivaria romana. ROMVLA. № 8. 199-225.

2012 Atenea y Medusa. Entre civilización y barbarie, Neira, L. (Coord. y Ed.), Civilización y barbarie. El mito como argumento en los mosaicos romanos, Madrid, Creaciones Vicent Gabrielle, pp. 69-82.

WOOLF, G.

2001 The Roman Cultural Revolution in Gaul. KEAY, S.; TERRENATO, N. Italy and the West: comparative issue in Romanization. Oxford: Oxbow Books, pp. 173-186.

2005 Provincial Perspective. GALINSKY, P. (Ed.). The Cambridge Companion of the age of Augustus. Cambridge University Press, p. 106-129

WALLACE-HADRLL, A.

1997 Mutatio morum: the idea of a cultural revolution. HABINEK,Th.; SCHIESARO, A. The Roman Cultural Revolution. Cambridge University Press, p. 3-22. 
